\title{
Regulatory $T$ cells induce activation rather than suppression of human basophils
}

Summary: Human basophils are refractory to suppression by Tregs and undergo activation by IL-3 and STAT5-dependent mechanism

\section{Meenu Sharma, ${ }^{1,2, *}$ Mrinmoy Das, ${ }^{1, *}$ Emmanuel Stephen-Victor, ${ }^{1, *}$ Caroline Galeotti, ${ }^{1}$ Anupama Karnam, ${ }^{1}$ Mohan S Maddur, ${ }^{1}$ Patrick Bruneval, ${ }^{3}$ Srini V Kaveri, ${ }^{1,4}$ Jagadeesh Bayry, 1,4, II}

\footnotetext{
${ }^{1}$ Institut National de la Santé et de la Recherche Médicale; Centre de Recherche des Cordeliers, Equipe- Immunopathologie et Immunointervention Thérapeutique; Sorbonne Université, Paris, F75006, France

${ }^{2}$ Université de Technologie de Compiègne, Compiègne, F-60205, France

${ }^{3}$ Service d'anatomie pathologique, Hôpital Européen Georges Pompidou, Paris, F-75015, France

${ }^{4}$ Université Paris Descartes, Sorbonne Paris Cité, Paris, F-75006, France

* These authors contributed equally to this work
}

II Corresponding author: Jagadeesh Bayry, Institut National de la Santé et de la Recherche Médicale Unité 1138, Centre de Recherche des Cordeliers, 15 rue de 1'Ecole de Médicine, Paris, F-75006, France. Tel: 00331442782 03; Fax: 00331442781 94;

E-mail: jagadeesh.bayry@crc.jussieu.fr 


\begin{abstract}
Basophils are a rare granulocyte population that have been associated with allergic and inflammatory responses. It is essential to understand the regulatory mechanisms by which basophils are kept in check, considering the impact of dysregulated basophil function on immune responses under different pathological conditions. Among immunoregulatory cells, $\mathrm{CD}^{+} \mathrm{CD} 25^{+} \mathrm{FoxP}^{+}$regulatory $\mathrm{T}$ cells (Tregs) are the key players that maintain immune tolerance. The mechanisms by which Tregs regulate and suppress diverse immune cell subsets have been studied extensively, but the impact of Tregs on basophil functions is not well understood. We report that human basophils are refractory to Treg-mediated suppression and found that Tregs stimulate resting basophils to induce the expression of activation markers including CD69, CD203c and CD13, and the release of basophil cytokines including IL-13, IL-8 and IL-4. Mechanistically, Tregs could induce human basophil activation via IL-3 and STAT5 activation, whereas cellular contact was dispensable. Inhibition of either IL-3-IL-3 receptor interactions or STAT5 phosphorylation abrogated Treg-mediated activation of basophils. These results provide evidence of direct positive effects that human Tregs have on basophil activation and reveal a previously unrecognized feature of this cell subset well known for immunosuppressive functions.
\end{abstract}




\section{INTRODUCTION}

Basophils are rare granulocytes (approximately $0.5 \%$ of total leukocytes) that are important for the protection against helminth parasites. In addition, basophils mediate Th2 responses, support B cell differentiation and enhance humoral responses $(1,2)$. Activated basophils produce several immunoregulatory cytokines such as IL-4, IL-13, IL-6, TSLP (Thymic stromal lymphopoietin) and BAFF (B-cell-activating factor) $(1,2)$. Through these mediators, basophils regulate $\mathrm{T}$ and $\mathrm{B}$ cell responses and are a critical link between innate and adaptive immunity $(3,4)$.

Although rare in number, basophils are implicated in various pathological conditions in part due to their ability to undergo rapid activation in response to a wide range of stimuli and release of diverse immune mediators. Basophils are well known for their pathogenic role in allergic conditions through secretion of mediators of hypersensitivity reactions including histamine and leukotriene $(1,2,5)$. Many inflammatory skin diseases are characterized by basophil infiltration and activation (6). Basophils are also reported to play a role in the pathogenesis of autoimmune and other inflammatory diseases (7-11). Therefore, considering the impact of dysregulated functions of basophils on the immune response in various diseases, it is essential to understand the regulatory mechanisms by which basophils are kept in check.

In this regard, regulatory $\mathrm{T}$ cells (Tregs) have been widely studied for their role in immune tolerance and in the maintenance of immune homeostasis (12-14). Tregs modulate autoimmune and inflammatory responses by exerting direct suppressive effects on various immune cells including dendritic cells (DCs), T cells, macrophages, monocytes, B cells, NK cells and mast cells (15-19). These functions are mediated by inhibitory surface molecules (cytotoxic $\mathrm{T}$ 
lymphocyte antigen-4 (CTLA-4) and lymphocyte-activation gene-3 (LAG-3)), inhibitory cytokines (TGF- $\beta$, IL-10 and IL-35) and cytotoxic molecules (granzyme and perforin). Although regulatory mechanisms by which Tregs suppress different immune cell subsets is an area of indepth study, the impact of Tregs on basophil function is not well understood. In view of emerging reports on the role of basophils in various pathological conditions, we investigated the interaction of Tregs with human basophils and its effects on basophil functions.

Here we report that in contrast to other immune cells, human basophils are refractory to Tregmediated suppression. Tregs did not inhibit anti-IgE-mediated activation of basophils. Surprisingly, we found that Tregs induce activation of resting basophils characterized by significantly enhanced expression of activation markers and secretion of several basophil cytokines such as IL-13, IL-8 and IL-4. Mechanistically, these stimulatory functions of Tregs were mediated via IL-3 released from the activated Tregs that triggered STAT5 pathway while cell-to-cell contact was dispensable. Inhibition of either IL-3-IL-3 receptor (CD123) interaction or STAT5 phosphorylation abrogated Treg-induced activation of basophils. These results demonstrate the direct positive effects of human Tregs on basophil activation and uncover previously unrecognized features of these immunosuppressor cells. 


\section{RESULTS}

\section{Human basophils are refractory to Treg-mediated suppression}

As Tregs are classically known for their immunosuppressive functions, we first evaluated the ability of human Tregs to suppress FceRI-mediated basophil activation. In our assays, we used activated memory Tregs that have the ability to directly suppress target cells without need for undergoing differentiation process (20). Stimulation of basophils with anti-IgE antibodies that crosslink FceRI-bound IgE on the basophils led to significant increase in the expression of various activation markers including CD203c, CD13 and CD69, and degranulation-associated markers CD63 and CD107a (Fig. 1A-H). Surprisingly, Tregs did not inhibit anti-IgE-mediated activation of basophils and the expression of various activation-associated markers on 'Tregeducated' basophils were on par with that of anti-IgE-stimulated control basophils and 'Tconveducated' basophils (Fig. 1A-H).

The effect of Tregs on the phenotype of basophils is reproduced in functional assays. We found that Tregs did not inhibit histamine release from anti-IgE-activated basophils (Fig. 1I). These results indicate that human basophils are refractory to Treg-mediated suppression.

\section{Human basophils lack receptors to receive contact-dependent inhibitory signals from Tregs}

We examined possible factors contributing to resistance of human basophils to Treg-mediated suppression. Suppression of target immune cells by Tregs is attributed to both contact-dependent and -independent mechanisms $(15,21-24)$. CTLA-4 and LAG-3 play a critical role in contactdependent suppression of target cells by Tregs through interaction with CD80/CD86 and HLADR respectively $(18,25,26)$. However, human basophils from the circulation (Fig. 2A) (27-30) and from secondary lymphoid organs such as spleen (Fig. 2B) (31) lack expression of HLA-DR 
and B7 co-stimulatory molecules under steady state as well as under stimulation conditions, although lipopolysaccharide-stimulated DCs, used as positive control, were all positive for these molecules (fig. S1). These results imply that the inability of Tregs to suppress activation of human basophils is in part due to absence of necessary receptors on basophils required to receive inhibitory signals. In addition, no significant differences in the viability of human basophils were observed when they co-cultured with Tregs (Fig. 2C and D).

\section{Human basophils are unresponsive to contact-independent inhibition by Tregs}

Several studies have demonstrated that Tregs mediate immune suppressive functions by cytokines, and in particular, TGF- $\beta$ and IL-10 $(21,32,33)$. The lack of suppressive effects of Tregs on human basophils raised an intriguing question on the expression of receptors for these cytokines. We found that circulating human basophils lack TGF- $\beta$ RII (Fig. 2E), but, IL-10R $\alpha$ was expressed on a subset of circulating human basophils $(40.3 \pm 6.6 \%, \mathrm{n}=6$ donors) (Fig. 2E). Similar patterns of expression were observed on human splenic basophils (fig. S2).

We explored if the IL-10R $\alpha^{+}$subset of human basophils could be modulated by IL-10. Basophils were treated with increasing concentrations of IL-10 (from $100 \mathrm{pg}$ to $10 \mathrm{ng} / \mathrm{ml}$ ) for 24 hours and then stimulated with anti-IgE during the last hour of culture. Even at the highest concentration (10 ng/ml), IL-10 did not modify the expression of activation markers on IL-10R $\alpha^{+}$or IL-10R $\alpha^{-}$ basophil subsets (Fig. 2F). IL-10 suppressed the expression of various activation markers on DCs, thus confirming the biological activity of this cytokine (fig. S3). Another report also indicated that IL-10 does not affect either IL-3 or IgE-mediated activation of human basophils 
(34). These results provide a potential explanation for the refractoriness of human basophils to Treg-mediated suppression.

\section{Tregs induce activation of resting basophils}

Since Tregs did not inhibit activation of human basophils, we examined the impact of activated Tregs co-cultured with resting basophils in the absence of any exogenous stimulation or cytokines for 24 hours. Tregs induced activation of human basophils as indicated by dramatically increased expression of the activation markers CD13, CD203c and CD69 (Fig. 3A and B). However, expression of CD63 and CD107a, the markers associated with basophil degranulation remain unaltered (Fig. 3C and D), indicating that Treg-induced activation of human basophils is not associated with degranulation. We confirmed that enhanced expression of activation markers on basophils upon co-culture with Tregs was not due to non-specific stimulation of basophils by anti-CD3 and anti-CD28 MAbs used for the activation of Tregs as the phenotype of basophils was not altered when they were cultured with these MAbs (fig. S4).

Treg-induced activation of human basophils was not restricted to phenotypic changes and functional analysis of basophils also confirmed their activation. Tregs significantly induced the secretion of IL-13 and IL-8 from basophils (Fig. 4A and B). Although significant, induction of IL-4 was minimum (Fig. 4C). Analysis of cytokines produced by activated Tregs alone at equivalent numbers revealed that they produced minimal amounts of IL-13 $(13.1 \pm 4.4 \mathrm{pg} / \mathrm{ml}$, mean \pm SEM, $\mathrm{n}=8)$, IL-8 $(13.5 \pm 5.1 \mathrm{pg} / \mathrm{ml}, \mathrm{n}=8)$ and IL-4 $(7.3 \pm 3.0 \mathrm{pg} / \mathrm{ml}, \mathrm{n}=8$ donors $)$. Together, these results demonstrate that Tregs induce activation of human basophils evidenced by phenotypic changes and secretion of cytokines (Fig. 3 and 4). 


\section{Cell adhesion is dispensable for Treg-induced activation of human basophils}

We aimed to identify the mechanism(s) by which Tregs induce activation of human basophils. Interaction of LFA-1 (CD11a/CD18) on Tregs with ICAM-1 (CD54) mediates adhesion and aggregation of Tregs on DCs (35-37). Previous studies have reported the expression of ICAM-1 on basophil cell lines and circulating human basophils $(38,39)$. We confirmed expression of ICAM-1 on resting human basophils, which was enhanced upon IL-3 stimulation (Fig. 5A). ICAM-1 blockade did not abrogate Treg-induced activation of basophils (Fig. 5B-D), and we confirmed that ICAM-1 blocking antibodies were functional as they inhibited DC-mediated proliferation of $\mathrm{CD}^{+} \mathrm{T}$ cells (fig. S5). IL-3-stimulated human basophils expressed ICOSL (fig. S6A) but ICOSL blockade had no significant effect on Treg-mediated basophil activation (fig. S6B). These results suggest that adhesion of Tregs to basophils is dispensable for Treg-induced activation of basophils.

We performed transwell experiments to confirm that cell-to-cell contact is dispensable for stimulating basophil activation by Tregs. Pre-activated Tregs were placed in the upper chamber and basophils in the lower chamber of the transwell system. Tregs in transwells induced significant expression of basophil activation markers (CD13, CD203c and CD69). The expression levels of activation markers were equivalent to levels induced on basophils cocultured with Tregs without transwell conditions (Fig. 5E). The leak-proof nature of transwell was confirmed by the absence of $\mathrm{CD}^{+} \mathrm{T}$ cells in the lower chambers of transwell (fig. S7). 


\section{Soluble mediators released from activated Tregs stimulate basophils}

Since cell contact was found not to be required for Treg-induced human basophil activation, we explored if soluble mediators released by activated Tregs mediate basophil stimulation. To examine this, we cultured resting basophils with cell-free supernatants from either unstimulated or anti-CD3/anti-CD28-stimulated Tregs. Supernatants from unstimulated Tregs did not modify the expression of activation markers on basophils (Fig. 6). However, basophils cultured with the supernatants from stimulated Tregs showed significantly enhanced expression of CD13, CD203c and CD69 (Fig. 6A), but not degranulation-associated markers CD63 and CD107a (Fig. 6B). The expression pattern of these activation markers was identical to basophils co-cultured with activated Tregs (Fig. 3). These results thus confirm a role for soluble mediator(s) released from activated Tregs in stimulating basophil activation.

\section{Tregs induce human basophil activation by IL-3-dependent mechanism}

Previous reports have shown that IL-3 plays a crucial role not only in the survival $(40,41)$ but in the activation of basophils $(39,42,43)$. IL-3 directly induces and enhances several activationlinked markers on human basophils such as CD69, CD203c and CD13 $(39,44)$ and stimulates secretion of cytokines including IL-13 (45). In fact, the expression of activation markers and secretion of cytokines by human basophils co-cultured with Tregs were reminiscent of IL-3 activity on basophils.

Several recent articles identified activated $\mathrm{CD}^{+} \mathrm{T}$ cells as a major source of IL-3 (46-48). We found that anti-CD3/anti-CD28-activated Tregs secrete IL-3 in the range of $148 \pm 25 \mathrm{pg} / \mathrm{million}$ cells (mean \pm SEM, $\mathrm{n}=11$ donors) while resting Tregs did not secrete detectable levels of IL-3 
(fig. S8). A dose-response study indicated that treatment of human basophils with IL-3 at a concentration equivalent to that secreted by human Tregs could induce activation (fig. S9). This data thus validates that the quantity of IL-3 produced by Tregs is sufficient to induce basophil activation.

To demonstrate unequivocally that Tregs induce human basophil activation by an IL-3dependent mechanism, we followed two independent approaches: blockade of IL-3 interaction with its receptor (IL-3R), and inhibition of IL-3-mediated signal transduction pathway. First, we blocked IL-3R on basophils before co-culture with activated Tregs. Consistent with our hypothesis, the expression of Treg-induced activation markers CD203c, CD13, CD69 and FceRI on basophils was significantly reduced upon IL-3R blockade (Fig. 7A and B). In addition, IL-3R blockade also decreased Treg-induced secretion of IL-8 and IL-13 by basophils (Fig. 7C).

IL-3 promotes priming of basophils for FceRI-mediated degranulation and for the release of inflammatory mediators. In response to degranulation signals, Treg-activated basophils showed significantly enhanced expression of degranulation-associated molecules CD107a and CD63, and released histamine at levels similar to that observed with IL-3-FceRI-activated basophils (fig. S10). These data confirm that Treg-activated basophils are functionally fit and that Tregs license basophils to undergo activation by degranulation signals.

To further authenticate that IL-3 signaling is implicated in the Treg-mediated activation of basophils, we investigated STAT5 pathway (34). Tregs induced phosphorylation of STAT5 in basophils at levels similar to that observed by treatment with IL-3 used at an equivalent 
concentration produced by stimulated Tregs (Fig. 8A and B). Importantly, STAT5 inhibition in basophils led to abrogation of Treg-induced activation markers CD13, CD203c and CD69 on basophils (Fig. 8C) and the secretion of IL-13 and IL-8 (Fig. 8D). These data together demonstrate that IL-3 plays a critical role in inducing Treg-mediated activation of human basophils. 


\section{DISCUSSION}

In the present study we found that human basophils not only show unique refractoriness towards Treg-mediated suppressive effects but also undergo activation by Tregs. In mice, basophils and antigen-specific $\mathrm{T}$ cells were reported to be engaged in multiple serial interactions of short to moderate duration in the tissues (47). However, mouse and human basophils display differences in the expression of co-stimulatory and antigen-presenting molecules that play a critical role in the cross-talk between innate cells and T cells $(27-30,49-53)$. Therefore, cognate interaction as in the case of classical antigen-presenting cells (APCs) and Tregs (54) is unlikely in the case of human basophils. Both Tregs and basophils are present in secondary lymphoid organs as well as in the peripheral tissues $(31,55,56)$. In these sites, Tregs constantly receive activation signals from APCs leading to the secretion of IL-3. Consequently, without involving cognate interaction, IL-3 secreted from activated Tregs could impact basophils both at secondary lymphoid organs and peripheral tissues.

Basophils play an important role in the protection against helminth parasites and various lines of evidence provide a pointer that IL-3 is central for these functions by supporting survival of basophils and promoting basophilia (57-59). IL-3 synergizes with basophil-derived IL-4 and IL13 to promote the alternative activation of monocytes (60). Alternative or M2 type monocytemacrophages are well recognized for their anti-inflammatory functions and for protection against nematode parasite (61). Thus, we propose that in vivo, under physiological conditions, Tregs might contribute to controlling the inflammation and to fight helminth infection by promoting basophilia and by enhancing the survival and activation of basophils via IL-3-dependent mechanism and by inducing IL-4 and IL-13. Although activation of human basophils by Tregs 
led to induction of these cytokines, the effect on IL-13 secretion was particularly prominent. Based on the current evidence it appears that IL-4 response by human basophils is mostly dependent on IgE/FceRI cross-linking. However, IL-13 could be induced in basophils by IgE/FceRI-independent signaling as well (62). In this regard, IL-3 has been reported to provide adequate stimulus to induce IL-13 secretion by human basophils $(44,63)$. As Tregs induced activation of human basophils via IL-3-dependent mechanism, it provides an explanation for low induction of IL-4 and higher secretion of IL-13 by basophils. Abrogation of IL-13 (and IL-8) production by basophils either upon IL-3R blockade or STAT5 inhibition further validates that these cytokines are contributed mainly by basophils.

Our study is limited to polyclonal $\mathrm{CD} 4^{+} \mathrm{CD} 25^{+} \mathrm{FoxP} 3^{+}$memory Tregs from the circulation of healthy donors. However, Tregs are highly diverse and in addition to FoxP3- Tregs (like Tr1 cells), several distinct subsets of Fox $3^{+}$Tregs have been identified. FoxP3 ${ }^{+}$human bonafide Tregs in the circulation consists of CD45RA ${ }^{-}$FoxP $3{ }^{\text {hi }} \mathrm{CD} 4{ }^{+}$activated and $\mathrm{CD} 45 \mathrm{RA}^{+} \mathrm{FoxP} 3{ }^{{ }^{l o}} \mathrm{CD} 4{ }^{+}$ resting Tregs (20). Moreover, based on the expression of chemokine receptors CXCR3, CCR4, CCR10, and CCR6, memory Tregs were further classified into various effector Th-like Treg subsets (Th1-Treg, Th2-Treg, Th17-Treg and Th1/Th17 Treg) that are immunosuppressive, FoxP $3^{+}$but secrete effector cytokine(s) of a corresponding Th subset (64-68). Therefore, it is likely that IL-3 secretion pattern might vary among these distinct Treg subsets and as a consequence their effect on basophil activation. Additionally, IL-3 production by Tregs might also be influenced by signals they receive in the microenvironment and in particular, signals by basophils. Detailed analyses of the influence of basophils on Treg plasticity, phenotype, functions and cytokine secretion pattern, particularly IL-3, should shed light on these points. 
Although chronic inflammation promotes pathogenic reprograming of Tregs into Th cells (69, 70), this might not be the case in our study as basophils-Tregs were cultured only for 24 hours. Another area that requires further exploration is whether IL-3 production and suppressive functions of Tregs are connected or independent process. In fact, it was suggested that reduced number and/or function of $\mathrm{FoxP}^{+}$Tregs in several immunodeficiencies such as immunodysregulation, polyendocrinopathy, enteropathy, X-linked (IPEX), Omenn syndrome and Wiskott-Aldrich syndrome leads to enhanced Th2 cytokine production and as a consequence increased IgE levels (71). Defective functions of Tregs are also reported in diverse autoimmune and inflammatory diseases (72). A comparative analysis of Treg functions and IL-3 production in healthy versus immunodeficient and autoimmune patients, and their repercussion on basophil functions need to be performed.

Multiple subsets of Tregs play an important role in the suppression of allergic responses both during sensitization phase and effector phase by targeting various cell types (73). Few reports however indicated that frequency of $\mathrm{CD} 4{ }^{+} \mathrm{CD} 25^{+}$Tregs is increased in patients with allergic rhinitis, atopic dermatitis, atopic and bronchial asthma (74-76). In addition, the number of Tregs has increased during exacerbation of asthma and allergic rhinitis $(75,76)$. Although, increased Tregs observed in these patients might represent response of the host to curtail pathogenic responses, our current data on the contrary suggests that enhanced Treg response observed in these patients might even aggravate allergic responses by activating basophils in an IL-3 dependent manner to induce IL-13 and IL-4 that are Th2-associated cytokines and support IgE class-switch. In fact, the Treg number in pediatric patients with allergic rhinitis and bronchial asthma was reported to correlate positively with total $\operatorname{IgE}$ level (75). It is therefore likely that 
various specialized subsets of regulatory cells participate in the regulation of different arms of allergic response and that a particular Treg subset alone might not efficiently control allergic responses (77-80). For example, in allergic rhinitis patients, deficiency of allergen-specific IL-10 producing Tr1 subset found to be associated with disease severity, though number and function of $\mathrm{CD} 4{ }^{+} \mathrm{CD} 25^{+}$Tregs in these patients did not change (81). Therefore, detailed investigation of various Treg subsets is crucial for establishing their correlation with diseases severity in allergic diseases. Considering that $\mathrm{CD} 4^{+} \mathrm{CD} 25^{+} \mathrm{FoxP}^{+}$Tregs activate basophils and could license them to undergo degranulation leading to histamine release, we suggest that simultaneous blocking of basophil responses is necessary to attain maximum benefits of Treg-targeted therapeutic approaches in allergic conditions. 


\section{MATERIALS AND METHODS}

\section{Study design}

This research was designed to investigate the regulation of human basophil functions by $\mathrm{CD}^{+} \mathrm{CD} 25^{+}$FoxP $^{+}$Tregs and underlying mechanisms. Cells were isolated from the buffy bags of healthy adult blood donors. As there was no intervention, blinding and randomization were not used. Depending on the number of experimental groups, our experimental design used repeated-measures analysis of variance (ANOVA) or Student's-t-test to measure the level of significance. Acquisition of data from multiple independent donors for each of the parameters permitted us to control inter-individual variations in the experiments.

\section{Isolation of basophils}

Buffy bags of healthy donors were subjected to Ficoll density gradient centrifugation and cellular fractions containing peripheral blood mononuclear cells (PBMCs) and basophils were collected. Basophils were isolated from these cells by using basophil isolation kit II (Miltenyi Biotec) and autoMACS $^{\circledR}$. The purity of basophils was $96 \pm 0.5 \%$ as analyzed by flow cytometry.

\section{Regulatory $\mathbf{T}$ cells}

For the isolation of $\mathrm{CD} 4^{+} \mathrm{CD} 45 \mathrm{RO}^{+} \mathrm{CD} 25^{+}$Tregs, untouched $\mathrm{CD} 4^{+} \mathrm{T}$ cells were first purified $\left(\mathrm{CD}^{+} \mathrm{T}\right.$ cell isolation kit II; Miltenyi Biotec) followed by isolation of untouched memory $\mathrm{T}$ cells $\left(\mathrm{CD}^{4} \mathrm{RO}^{+}\right)$by depletion of naïve T cells using CD45RA microbeads (Miltenyi Biotec). Further, CD $25^{+}$Tregs were positively selected from these memory $\mathrm{T}$ cells by CD25 microbeads (Miltenyi Biotec). Tregs were confirmed by phenotype analysis of various markers (fig. S11A) and by functional assays as detailed below (fig. S11B). CD $4^{+} \mathrm{CD} 45 \mathrm{RO}^{+} \mathrm{CD} 25^{-/ \mathrm{lo}} \mathrm{T}$ cell fraction 
was used as conventional T cells (Tconv) for the comparison with Tregs (fig. S11). The purity of various T cell populations was $96 \pm 3 \%$.

\section{CFSE-labelling of $\mathrm{CD4}^{+} \mathrm{T}$ cells}

$\mathrm{CD}^{+} \mathrm{T}$ cells were washed and resuspended in PBS $\left(10 \times 10^{6}\right.$ cells $\left./ \mathrm{ml}\right)$. Cells were incubated with carboxyfluorescein succinimidyl ester (CFSE, $5 \mu \mathrm{M}$, BD Biosciences) at $37^{\circ} \mathrm{C}$ in a water bath for 10 minutes followed by thorough washing with the medium. Labelled CD4 ${ }^{+} \mathrm{T}$ cells were resuspended in X-VIVO medium at a concentration of $10^{6}$ cells $/ \mathrm{ml}$.

\section{Treg suppression assay}

For analyzing the suppression of Tconv proliferation by Tregs (fig. S11B), CFSE-labelled Tconv cells were cultured in serum-free X-VIVO 15 medium either alone $\left(0.1 \times 10^{6}\right.$ cells $\left./ 200 \mu \mathrm{L}\right)$ or with Tregs at 1:3 ratio in the presence of plate-bound anti-CD3 MAb $(1 \mu \mathrm{g} / \mathrm{ml})$ and soluble antiCD28 MAb $(1 \mu \mathrm{g} / \mathrm{ml})$. After five days, proliferation of Tconv cells was analyzed by flow cytometry based on the dilution of CFSE.

\section{Co-culture of basophils with Tregs or Tconv}

To investigate the effect of Tregs on anti-IgE-mediated activation of human basophils, basophils $\left(0.1 \times 10^{6}\right.$ cells/well/200 $\left.\mu \mathrm{L}\right)$ were cultured in 96 well U-bottomed plate either alone in serum-free X-VIVO 15 medium or with IL-3 (2 ng/0.1×10 cells, ImmunoTools) or with IL-3 plus Tregs or Tconv cells $\left(0.3 \times 10^{6}\right.$ cells/well/200 $\left.\mu \mathrm{L}\right)$ at $1: 3$ ratio for 24 hours. Tregs/Tconv in the co-culture conditions were stimulated with plate-bound anti-CD3 MAb $(1 \mu \mathrm{g} / \mathrm{ml})$ and soluble anti-CD28 MAb $(1 \mu \mathrm{g} / \mathrm{mL})$. During last one-hour culture, polyclonal affinity isolated anti-human $\operatorname{IgE}\left(\varepsilon^{-}\right.$ 
chain specific, Sigma-Aldrich) antibodies $\left(10 \mathrm{ng} / 0.1 \times 10^{6}\right.$ cells $)$ were added to stimulate the basophils.

For measuring the viability of cells by Annexin V and propidium iodide (PI, Sigma-Aldrich) staining, basophils were cultured for 24 hours in medium alone or with IL-3 or IL-3 plus antiCD3/anti-CD28-activated Tregs or Tconv. Basophils were also stimulated with anti-IgE antibodies during last one-hour of the culture. As a positive control for Annexin V and PI staining, PBMCs were treated with gemcitabine (Sigma-Aldrich, $1 \mu \mathrm{g} / 0.5 \times 10^{6}$ cells $/ \mathrm{ml}$ ) for 24 hours or $20 \%$ ethanol (200 $\mu \mathrm{L} / 0.5 \times 10^{6}$ cells $\left./ \mathrm{ml}\right)$ for 30 min respectively (fig. S12).

For the analysis of impact of Tregs on resting basophils, basophils $\left(0.1 \times 10^{6}\right.$ cells/well/200 $\left.\mu \mathrm{L}\right)$ were cultured either alone in serum-free X-VIVO 15 medium or co-cultured with Tregs $\left(0.3 \times 10^{6}\right.$ cells/well/200 $\mu \mathrm{L}$ ) at 1:3 ratio for 24 hours. Tregs in the co-culture were stimulated with platebound anti-CD3 MAb and soluble anti-CD28 MAb.

To investigate the implication of either surface molecules or soluble mediators in Treg-induced basophil activation, basophils $\left(0.1 \times 10^{6}\right.$ cells $)$ were either cultured alone in serum-free X-VIVO 15 medium or with Tregs $\left(0.3 \times 10^{6}\right.$ cells/well/200 $\left.\mu \mathrm{L}\right)$ or with Tregs in the presence of blocking MAbs (10 $\mu \mathrm{g} / \mathrm{ml})$ to ICAM-1, ICOSL or IL-3 receptor (CD123) or isotype control MAb for 24 hours. Tregs in the all the co-culture conditions were stimulated with anti-CD3 and anti-CD28 MAbs.

To analyze if soluble mediators released from Tregs induce basophil activation, Tregs $\left(0.3 \times 10^{6}\right.$ cells) were either cultured alone (resting phase) in serum-free X-VIVO 15 medium or were stimulated with anti-CD3 and anti-CD28 MAbs for 24 hours. Cell-free culture supernatants were harvested and basophils $\left(0.1 \times 10^{6}\right.$ cells/well $)$ were cultured for 24 hours either alone in serumfree X-VIVO 15 medium or in the presence of supernatants obtained from unstimulated or 
stimulated Tregs.

For transwell experiments, Tregs $\left(0.3 \times 10^{6}\right.$ cells $\left./ 100 \mu \mathrm{L}\right)$ were pre-activated with anti-CD3 and anti-CD28 MAbs for 24 hours. Basophils were placed in the lower chambers of transwells (Transwell ${ }^{\circledR}, 0.4 \mu \mathrm{m}$, Corning) and pre-activated Tregs were added to the upper chambers of transwell. The cells were cultured for 24 hours.

To analyze STAT5 activation, basophils were co-cultured with pre-activated Tregs $\left(0.3 \times 10^{6}\right.$ cells $/ 200 \mu \mathrm{L})$ at $1: 3$ ratio for 6 hours. As a positive control, basophils $\left(0.1 \times 10^{6}\right.$ cells $\left./ 200 \mu \mathrm{L}\right)$ were treated with IL-3 (100 pg/ml, an equivalent concentration produced by stimulated Tregs) for 6 hours. Cells were stained with anti-STAT5 (pY694) or isotype control MAbs by using Cell Signaling Buffer Set A (Miltenyi Biotec).

To confirm the role of STAT5 in Treg-induced basophil activation, basophils $\left(0.1 \times 10^{6}\right.$ cells/200 $\mu \mathrm{L})$ were pretreated with STAT5 inhibitor CAS 285986-31-4-Calbiochem (20 $\mu \mathrm{M}$, Merck Millipore) or equivalent volume of DMSO for 2 hours followed by co-culture with Tregs $\left(0.3 \times 10^{6}\right.$ cells $)$ for 24 hours. Tregs in the co-culture were stimulated with anti-CD3 and antiCD28 MAbs.

To determine whether Treg-activated basophils are functionally fit and Tregs license basophils to undergo activation by degranulation signals, basophils $\left(0.1 \times 10^{6}\right.$ cells $\left./ 200 \mu \mathrm{L}\right)$ were co-cultured with Tregs $\left(0.3 \times 10^{6}\right.$ cells $\left./ 200 \mu \mathrm{L}\right)$ for 24 hours in the presence of anti-CD3 and anti-CD28 MAbs. During last one-hour culture, anti-IgE antibodies (10 $\mathrm{ng} / 0.1 \times 10^{6}$ basophils) were added to stimulate the basophils.

Basophil response was examined by analyzing the expression of activation-associated markers by flow cytometry. Cell-free culture supernatants were collected from basophil-Treg co-culture experiments and subjected for the analysis of histamine or cytokines. 


\section{Treatment of basophils with IL-10}

Basophils $\left(0.1 \times 10^{6}\right.$ cells/well/200 $\left.\mu \mathrm{L}\right)$ were cultured in X-VIVO 15 medium either alone with IL-3 ( $2 \mathrm{ng} / 0.1 \times 10^{6}$ cells) or IL-3 plus increasing concentration of rhIL-10 (eBioscience) ranging from $100 \mathrm{pg} / \mathrm{ml}$ to $20 \mathrm{ng} / \mathrm{ml}$, for 24 hours. During last one-hour culture, anti-IgE antibodies (10 $\mathrm{ng} / 0.1 \times 10^{6}$ cells) were added to stimulate basophils and the expression of activation markers was analyzed by flow cytometry.

\section{Isolation of human splenocytes}

Spleen pieces were mechanically disaggregated by gentleMACS ${ }^{\mathrm{TM}}$ dissociator (Miltenyi Biotec, program $\mathrm{m} \_$spleen_04) and were then filtered through $70-\mu \mathrm{m}$ nylon membrane filter (BD Biosciences) to obtain single-cell suspension of splenocytes. Splenocytes were then processed through Ficoll-Paque density gradient centrifugation to remove red blood cells (RBC). RBCdepleted splenocytes were then washed two times with RPMI 1640. Splenic basophils were distinguished from mast cells $\left(\mathrm{CD} 117^{+}\right)$and DC subsets (BDCA 1-4 $4^{+}$) and the expression of HLA-DR, CD80, CD86, IL-10R $\alpha$ and TGF- $\beta$ RII on these CD203c ${ }^{+} F c \varepsilon R I^{+}$splenic-basophils was analyzed by flow cytometry.

\section{Culture of dendritic cells}

Monocytes from PBMC were isolated by using CD14 microbeads (Miltenyi Biotec). Monocytes were differentiated to DCs by culturing them with rhIL-4 (500 IU/10 ${ }^{6}$ cells) and rhGM-CSF (1000 IU/10 6 cells) (both from Miltenyi Biotec) for six days. Differentiation of DCs was confirmed by the analysis of surface markers. In addition, DCs were also stimulated with lipopolysaccharide from Escherichia coli O55:B5 (10 ng/0.5×10 cells, Sigma-Aldrich) for 24 
hours and analyzed for the expression of maturation-associated markers.

To analyze the effect of IL-10 on DCs, cells were treated with rhIL-10 (10 ng/ml/0.5 $\times 10^{6}$ cells) for 24 hours followed by analysis of surface markers by flow-cytometry.

To explore the effect of ICAM-1 blockade towards DC-mediated $\mathrm{CD} 4^{+} \mathrm{T}$ cell proliferation, DCs were pre-incubated with ICAM-1 blocking MAb $(20 \mu \mathrm{g} / \mathrm{ml})$ or isotype control MAb for 2 hours followed by co-culture with CFSE-labelled allogeneic $C D 4^{+} \mathrm{T}$ cells $\left(0.1 \times 10^{6} \mathrm{~T}\right.$ cells/well $)$ at 1:20 ratio in a total volume of $200 \mu \mathrm{L}$ for five days.

\section{Measurement of histamine and cytokines}

Histamine was measured in the culture supernatants by histamine EIA kit (Bertin Pharma). IL-3 (Quantikine ELISA kit, R\&D systems), IL-8, IL-13 and IL-4 (ELISA Ready-SET-Go, eBioscience) were analyzed in the culture supernatants by ELISA.

\section{Statistical analysis}

Statistical analyses were performed by GraphPad Prism 6 Software. Data were analyzed by oneway ANOVA with Tukey's multiple comparison tests $(\alpha=0.05)$ or two-tailed paired Student's ttest as indicated. Two-way ANOVA with Least Significant Difference was used to analyze Fig. 2F. Data are presented as mean $\pm \mathrm{SEM} . * \mathrm{P}<0.05, * * \mathrm{P}<0.01, * * * \mathrm{P}<0.001$, and $* * * * \mathrm{P}<0.0001$. 


\section{SUPPLEMENTARY MATERIALS}

Materials and Methods

Fig. S1. Expression of HLA-DR, CD80 and CD86 on human dendritic cells.

Fig. S2. Expression of TGF- $\beta$ RII and IL-10R $\alpha$ on human splenic basophils.

Fig. S3. Effect of IL-10 on the phenotype of human dendritic cells.

Fig. S4. Anti-CD3 and anti-CD28 MAbs do not alter the phenotype of basophils.

Fig. S5. Blocking of ICAM-1 on dendritic cells inhibits dendritic cell-mediated CD4 ${ }^{+} \mathrm{T}$ cell proliferation.

Fig. S6. ICOS-ICOSL interaction is dispensable for the Treg-mediated human basophil activation.

Fig. S7. Representative dot-plots depicting the absence of $\mathrm{CD}^{+} \mathrm{T}$ cells in the lower chambers of tranwells.

Fig. S8. IL-3 secretion by human Tregs.

Fig. S9. Dose-dependent effects of IL-3 on the phenotype of human basophils.

Fig. S10. Tregs license basophils to undergo activation by degranulation signals.

Fig. S11. The phenotypic and functional features of isolated human Tregs.

Fig. S12. The positive controls for Annexin V and PI staining.

Data file S1. Raw data from figure graphs (Excel). 


\section{REFERENCES AND NOTES}

1. H. Karasuyama, K. Mukai, K. Obata, Y. Tsujimura, T. Wada, Nonredundant roles of basophils in immunity. Annu. Rev. Immunol. 29, 45-69 (2011).

2. D. Voehringer, Protective and pathological roles of mast cells and basophils. Nat. Rev. Immunol. 13, 362-375 (2013).

3. H. Karasuyama, K. Mukai, Y. Tsujimura, K. Obata, Newly discovered roles for basophils: a neglected minority gains new respect. Nat. Rev. Immunol. 9, 9-13 (2009).

4. A. Denzel, U.A. Maus, M. Rodriguez Gomez, C. Moll, M. Niedermeier, C. Winter, R. Maus, S. Hollingshead, D.E. Briles, L.A. Kunz-Schughart, Y. Talke, M. Mack, Basophils enhance immunological memory responses. Nat. Immunol. 9, 733-742 (2008).

5. M.C. Siracusa, B.S. Kim, J.M. Spergel, D. Artis, Basophils and allergic inflammation. $J$. Allergy Clin. Immunol. 132, 789-801 (2013).

6. Y. Ito, T. Satoh, K. Takayama, C. Miyagishi, A.F. Walls, H. Yokozeki, Basophil recruitment and activation in inflammatory skin diseases. Allergy 66, 1107-1113 (2011).

7. M. Sharma, J. Bayry, Autoimmunity: Basophils in autoimmune and inflammatory diseases. Nat. Rev. Rheumatol. 11, 129-13 (2015).

8. N. Charles, D. Hardwick, E. Daugas, G.G. Illei, J. Rivera, Basophils and the T helper 2 environment can promote the development of lupus nephritis. Nat. Med. 16, 701-707 (2010).

9. Y. Kikuchi, A.P. Kaplan, Mechanisms of autoimmune activation of basophils in chronic urticaria. J. Allergy Clin. Immunol. 107, 1056-1062 (2001).

10. M. Noti, E.D. Wojno, B.S. Kim, M.C. Siracusa, P.R. Giacomin, M.G. Nair, A.J. Benitez, K.R. Ruymann, A.B. Muir, D.A. Hill, K.R. Chikwava, A.E. Moghaddam, Q.J. Sattentau, A. Alex, C. Zhou, J.H. Yearley, P. Menard-Katcher, M. Kubo, K. Obata-Ninomiya, H. Karasuyama, M.R. Comeau, T. Brown-Whitehorn, R. de Waal Malefyt, P.M. Sleiman, H. Hakonarson, A. Cianferoni, G.W. Falk, M.L. Wang, J.M. Spergel, D. Artis, Thymic stromal lymphopoietin-elicited basophil responses promote eosinophilic esophagitis. Nat. Med. 19, 1005-1013 (2013).

11. T. Watanabe, K. Yamashita, T. Sakurai, M. Kudo, M. Shiokawa, N. Uza, Y. Kodama, K. Uchida, K. Okazaki, T. Chiba, Toll-like receptor activation in basophils contributes to the development of IgG4-related disease. J. Gastroenterol. 48, 247-253 (2013).

12. S. Sakaguchi, T. Yamaguchi, T. Nomura, M. Ono, Regulatory T cells and immune tolerance. Cell 133, 775-787 (2008).

13. Q. Tang, K.J. Henriksen, M. Bi, E.B. Finger, G. Szot, J. Ye, E.L. Masteller, H. McDevitt, M. Bonyhadi, J.A. Bluestone, In vitro-expanded antigen-specific regulatory $\mathrm{T}$ cells suppress autoimmune diabetes. J. Exp. Med. 199, 1455-1465 (2004). 
14. H. Yu, R. Paiva, R.A. Flavell. Harnessing the power of regulatory T-cells to control autoimmune diabetes: overview and perspective. Immunology 153, 161-70 (2018).

15. Q. Tang, J.A. Bluestone, The Foxp $3^{+}$regulatory $\mathrm{T}$ cell: a jack of all trades, master of regulation. Nat. Immunol. 9, 239-244 (2008).

16. M.E. Turnis, D.V. Sawant, A.L. Szymczak-Workman, L.P. Andrews, G.M. Delgoffe, H. Yano, A.J. Beres, P. Vogel, C.J. Workman, D.A. Vignali, Interleukin-35 Limits AntiTumor Immunity. Immunity 44, 316-329 (2016).

17. I. Barao, A.M. Hanash, W. Hallett, L.A. Welniak, K. Sun, D. Redelman, B.R. Blazar, R.B. Levy, W.J. Murphy, Suppression of natural killer cell-mediated bone marrow cell rejection by $\mathrm{CD} 4{ }^{+} \mathrm{CD} 25^{+}$regulatory T cells. Proc. Natl. Acad. Sci. USA. 103, 5460-5465 (2006).

18. J. Bayry, F. Triebel, S.V. Kaveri, D.F. Tough, Human dendritic cells acquire a semimature phenotype and lymph node homing potential through interaction with $\mathrm{CD} 4^{+} \mathrm{CD} 25^{+}$ regulatory T cells. J. Immunol. 178, 4184-4193 (2007).

19. G. Gri, S. Piconese, B. Frossi, V. Manfroi, S. Merluzzi, C. Tripodo, A. Viola, S. Odom, J. Rivera, M.P. Colombo, C.E. Pucillo, $\mathrm{CD} 4^{+} \mathrm{CD} 25^{+}$regulatory $\mathrm{T}$ cells suppress mast cell degranulation and allergic responses through OX40-OX40L interaction. Immunity 29,771781 (2008).

20. M. Miyara, Y. Yoshioka, A. Kitoh, T. Shima, K.Wing, A. Niwa, C. Parizot, C. Taflin, T. Heike, D. Valeyre, A. Mathian, T. Nakahata, T. Yamaguchi, T. Nomura, M. Ono, Z. Amoura, G. Gorochov, S Sakaguchi, Functional delineation and differentiation dynamics of human CD4+ T cells expressing the FoxP3 transcription factor. Immunity 30, 899-911 (2009).

21. S. Sakaguchi, M. Miyara, C.M. Costantino, D.A. Hafler, FOXP3 ${ }^{+}$regulatory T cells in the human immune system. Nat. Rev. Immunol. 10, 490-500 (2010).

22. S.Z. Josefowicz, L.F. Lu, A.Y. Rudensky, Regulatory T cells: mechanisms of differentiation and function. Annu. Rev. Immunol. 30, 531-564 (2012).

23. E.M. Shevach, Mechanisms of Foxp $3^{+}$T regulatory cell-mediated suppression. Immunity 30, 636-645 (2009).

24. D.A. Vignali, L.W. Collison, C.J. Workman, How regulatory T cells work. Nat. Rev. Immunol. 8, 523-532 (2008).

25. K. Wing, Y. Onishi, P. Prieto-Martin, T. Yamaguchi, M. Miyara, Z. Fehervari, T. Nomura, S. Sakaguchi, CTLA-4 control over Foxp3 ${ }^{+}$regulatory T cell function. Science 322, 271275(2008).

26. B. Liang, C. Workman, J. Lee, C. Chew, B.M. Dale, L. Colonna, M. Flores, N. Li, E. Schweighoffer, S. Greenberg, V. Tybulewicz, D. Vignali, R. Clynes, Regulatory T cells inhibit dendritic cells by lymphocyte activation gene-3 engagement of MHC class II. $J$. Immunol. 180, 5916-5926 (2008). 
27. M. Sharma, P. Hegde, V. Aimanianda, R. Beau, M.S. Maddur, H. Senechal, P. Poncet, J.P. Latge, S.V. Kaveri, J. Bayry, Circulating human basophils lack the features of professional antigen presenting cells. Sci. Rep. 3, 1188 (2013).

28. C. Kitzmuller, B. Nagl, S. Deifl, C. Walterskirchen, B. Jahn-Schmid, G.J. Zlabinger, B. Bohle, Human blood basophils do not act as antigen-presenting cells for the major birch pollen allergen Bet v 1. Allergy 67, 593-600 (2012).

29. J. Eckl-Dorna, A. Ellinger, K. Blatt, V. Ghanim, I. Steiner, M. Pavelka, P. Valent, R. Valenta, V. Niederberger, Basophils are not the key antigen-presenting cells in allergic patients. Allergy 67, 601-608 (2012).

30. D. Dijkstra, C. Hennig, T. Witte, G. Hansen, Basophils from humans with systemic lupus erythematosus do not express MHC-II. Nat. Med. 18, 488-489 (2012).

31. E. Stephen-Victor, M. Das, M. Sharma, C. Galeotti, H. Fohrer-Ting, B. Sendid, L. Darnige, B. Terris, C. Badoual, P. Bruneval, S.V. Kaveri, J. Bayry, Demystification of enigma on antigen presenting cell features of human basophils: data from secondary lymphoid organs. Haematologica 102, e233-e237 (2017).

32. T. Ito, S. Hanabuchi, Y.H. Wang, W.R. Park, K. Arima, L. Bover, F.X. Qin, M. Gilliet, Y.J. Liu, Two functional subsets of $\mathrm{FOXP}^{+}$regulatory $\mathrm{T}$ cells in human thymus and periphery. Immunity 28, 870-880 (2008).

33. J. Andersson, D.Q. Tran, M. Pesu, T.S. Davidson, H. Ramsey, J.J. O'Shea, E.M. Shevach, $\mathrm{CD} 4{ }^{+} \mathrm{FoxP}^{+}$regulatory $\mathrm{T}$ cells confer infectious tolerance in a TGF- $\beta$-dependent manner. J. Exp. Med. 205, 1975-1981 (2008).

34. M.M. Verweij, V. Sabato, S. Nullens, C.H. Bridts, L.S. De Clerck, W.J. Stevens, D.G. Ebo, STAT5 in human basophils: IL-3 is required for its FceRI-mediated phosphorylation. Cytometry B Clin. Cytom. 82, 101-106 (2012).

35. Y. Onishi, Z. Fehervari, T. Yamaguchi, S. Sakaguchi, Foxp3 ${ }^{+}$natural regulatory T cells preferentially form aggregates on dendritic cells in vitro and actively inhibit their maturation. Proc. Natl. Acad. Sci. USA. 105, 10113-10118 (2008).

36. H. Wang, T. Peters, A. Sindrilaru, D. Kess, T. Oreshkova, X.Z. Yu, A.M. Seier, H. Schreiber, M. Wlaschek, R. Blakytny, J. Rohrbein, G. Schulz, J.M. Weiss, K. ScharffetterKochanek, TGF- $\beta$-dependent suppressive function of Tregs requires wild-type levels of CD18 in a mouse model of psoriasis. J. Clin. Invest. 118, 2629-2639 (2008).

37. D.Q. Tran, D.D. Glass, G. Uzel, D.A. Darnell, C. Spalding, S.M. Holland, E.M. Shevach, Analysis of adhesion molecules, target cells, and role of IL-2 in human $\mathrm{FOXP}^{+}$regulatory T cell suppressor function. J. Immunol. 182, 2929-2938 (2009).

38. P. Valent, J. Besemer, K. Kishi, R. Kaltenbrunner, B. Kuhn, D. Maurer, K. Lechner, P. Bettelheim, IL-3 promotes basophilic differentiation of KU812 cells through high affinity binding sites. J. Immunol. 145, 1885-1889 (1990). 
39. C. Yoshimura, M. Yamaguchi, M. Iikura, S. Izumi, K. Kudo, H. Nagase, A. Ishii, A.F. Walls, C. Ra, T. Iwata, T. Igarashi, K. Yamamoto, K. Hirai, Activation markers of human basophils: CD69 expression is strongly and preferentially induced by IL-3. J. Allergy Clin. Immunol. 109, 817-823 (2002).

40. S.A. Didichenko, N. Spiegl, T. Brunner, C.A. Dahinden, IL-3 induces a Pim1-dependent antiapoptotic pathway in primary human basophils. Blood 112, 3949-3958 (2008).

41. X. Zheng, A. Karsan, V. Duronio, F. Chu, D.C. Walker, T.R. Bai, R.R. Schellenberg, Interleukin-3, but not granulocyte-macrophage colony-stimulating factor and interleukin-5, inhibits apoptosis of human basophils through phosphatidylinositol 3-kinase: requirement of NF-kB-dependent and -independent pathways. Immunology 107, 306-315 (2002).

42. J.T. Schroeder, K.L. Chichester, A.P. Bieneman, Human basophils secrete IL-3: evidence of autocrine priming for phenotypic and functional responses in allergic disease. $J$. Immunol. 182, 2432-2438 (2009).

43. D. Voehringer, Basophil modulation by cytokine instruction. Eur. J. Immunol. 42, 25442550 (2012).

44. J.T. Schroeder, Basophils: emerging roles in the pathogenesis of allergic disease. Immunol. Rev. 242, 144-160 (2011).

45. Y.H. Chen, A.P. Bieneman, P.S. Creticos, K.L. Chichester, J.T. Schroeder, IFN- $\alpha$ inhibits IL-3 priming of human basophil cytokine secretion but not leukotriene $\mathrm{C} 4$ and histamine release. J. Allergy Clin. Immunol. 112, 944-950 (2003).

46. T. Shen, S. Kim, J.S. Do, L. Wang, C. Lantz, J.F. Urban, G. Le Gros, B. Min, T cellderived IL-3 plays key role in parasite infection-induced basophil production but is dispensable for in vivo basophil survival. Int. Immunol. 20,1201-1209 (2008).

47. B.M. Sullivan, H.E. Liang, J.K. Bando, D. Wu, L.E. Cheng, J.K. McKerrow, C.D. Allen, R.M. Locksley, Genetic analysis of basophil function in vivo. Nat. Immunol. 12, 527-535 (2011).

48. J.M. Leyva-Castillo, P. Hener, P. Michea, H. Karasuyama, S. Chan, V. Soumelis, M. Li, Skin thymic stromal lymphopoietin initiates Th2 responses through an orchestrated immune cascade. Nat. Commun. 4, 2847 (2013).

49. J.G. Perrigoue, S.A. Saenz, M.C. Siracusa, E.J. Allenspach, B.C. Taylor, P.R. Giacomin, M.G. Nair, Y. Du, C. Zaph, N. van Rooijen, M.R. Comeau, E.J. Pearce, T.M. Laufer, D. Artis, MHC class II-dependent basophil- $\mathrm{CD}^{+} \mathrm{T}$ cell interactions promote $\mathrm{T}_{\mathrm{H}} 2$ cytokinedependent immunity. Nat. Immunol. 10, 97-705 (2009).

50. C.L. Sokol, N.Q. Chu, S. Yu, S.A. Nish, T.M. Laufer, R. Medzhitov, Basophils function as antigen-presenting cells for an allergen-induced $\mathrm{T}$ helper type 2 response. Nat. Immunol. 10, 713-720 (2009). 
51. T. Yoshimoto, K. Yasuda, H. Tanaka, M. Nakahira, Y. Imai, Y. Fujimori, K. Nakanishi, Basophils contribute to $\mathrm{TH} 2-\mathrm{IgE}$ responses in vivo via IL-4 production and presentation of peptide-MHC class II complexes to CD4 ${ }^{+}$T cells. Nat. Immunol. 10, 706-712 (2009).

52. A. Otsuka, S. Nakajima, M. Kubo, G. Egawa, T. Honda, A. Kitoh, T. Nomura, S. Hanakawa, C. Sagita Moniaga, B. Kim, S. Matsuoka, T. Watanabe, Y. Miyachi, K. Kabashima, Basophils are required for the induction of Th2 immunity to haptens and peptide antigens. Nat. Commun. 4,1739 (2013).

53. K. Miyake, N. Shiozawa, T. Nagao, S. Yoshikawa, Y. Yamanishi, H. Karasuyama, Trogocytosis of peptide-MHC class II complexes from dendritic cells confers antigenpresenting ability on basophils. Proc. Natl. Acad. Sci. USA. 114, 1111-1116 (2017).

54. Q. Tang, J.Y. Adams, A.J. Tooley, M. Bi, B.T. Fife, P. Serra, P. Santamaria, R.M. Locksley, M.F. Krummel, J.A. Bluestone, Visualizing regulatory $\mathrm{T}$ cell control of autoimmune responses in nonobese diabetic mice. Nat. Immunol. 7, 83-92 (2006).

55. D. Burzyn, C. Benoist, D. Mathis, Regulatory $\mathrm{T}$ cells in nonlymphoid tissues. Nat. Immunol. 14, 1007-1013 (2013).

56. J.H. Peters, H.J. Koenen, E. Fasse, H.J. Tijssen, J.N. Ijzermans, P.J. Groenen, N.P. Schaap, J. Kwekkeboom, I. Joosten, Human secondary lymphoid organs typically contain polyclonally-activated proliferating regulatory T cells. Blood 122, 2213-2223 (2013).

57. C.S. Lantz, J. Boesiger, C.H. Song, N. Mach, T. Kobayashi, R.C. Mulligan, Y. Nawa, G. Dranoff, S.J. Galli, Role for interleukin-3 in mast-cell and basophil development and in immunity to parasites. Nature 392, 90-93 (1998).

58. C.S. Lantz, B. Min, M. Tsai, D. Chatterjea, G. Dranoff, S.J. Galli, IL-3 is required for increases in blood basophils in nematode infection in mice and can enhance IgE-dependent IL-4 production by basophils in vitro. Lab. Invest. 88, 1134-1142 (2008).

59. T. Herbst, J. Esser, M. Prati, M. Kulagin, R. Stettler, M.M. Zaiss, J.P. Hewitson, P. Merky, J.S. Verbeek, C. Bourquin, M. Camberis, M. Prout, R.M. Maizels, G. Le Gros, N.L. Harris, Antibodies and IL-3 support helminth-induced basophil expansion. Proc. Natl. Acad. Sci. USA. 109, 14954-14959 (2012).

60. F. Borriello, M. Longo, R. Spinelli, A. Pecoraro, F. Granata, R.I. Staiano, S. Loffredo, G. Spadaro, F. Beguinot, J. Schroeder, G. Marone, IL-3 synergises with basophil-derived IL-4 and IL-13 to promote the alternative activation of human monocytes. Eur. J. Immunol. 45, 2042-2051 (2015).

61. R.M. Anthony, J.F. Urban Jr, F. Alem, H.A. Hamed, C.T. Rozo, J.L. Boucher, N. Van Rooijen, W.C. Gause. Memory $\mathrm{T}_{\mathrm{H}} 2$ cells induce alternatively activated macrophages to mediate protection against nematode parasites. Nat. Med. 12, 955-60 (2006). 
62. B. Ochensberger, G.C. Daepp, S. Rihs, C.A. Dahinden, Human blood basophils produce interleukin-13 in response to IgE-receptor-dependent and -independent activation. Blood 88, 3028- 3037 (1996).

63. A.C. Redrup, B.P. Howard, D.W. Jr. MacGlashan, A. Kagey-Sobotka, L.M. Lichtenstein, J.T. Schroeder, Differential regulation of IL-4 and IL-13 secretion by human basophils: their relationship to histamine release in mixed leukocyte cultures. J. Immunol. 160,19571964 (1998).

64. G. Beriou, C.M. Costantino, C.W. Ashley, L. Yang, V.K. Kuchroo, C. Baecher-Allan, D.A. Hafler, IL-17-producing human peripheral regulatory $\mathrm{T}$ cells retain suppressive function. Blood 113, 4240-4249 (2009).

65. K.S. Voo, Y.H. Wang, F.R.Santori, C. Boggiano, Y.H. Wang, K. Arima, L. Bover, S. Hanabuchi, J. Khalili, E. Marinova, B. Zheng, D.R. Littman, Y.J. Liu, Identification of IL17-producing FOXP3 ${ }^{+}$regulatory T cells in humans. Proc Natl Acad Sci. USA. 106, 47934798 (2009).

66. T. Duhen, R. Duhen, A. Lanzavecchia, F. Sallusto, D.J. Campbell, Functionally distinct subsets of human FOXP3 ${ }^{+}$Treg cells that phenotypically mirror effector Th cells. Blood 119, 4430-4440 (2012).

67. R.K. Venigalla, P.J. Guttikonda, V. Eckstein, A.D. Ho, S. Sertel, H.M. Lorenz, T. Tretter, Identification of a human Th1-like IFN $\gamma$-secreting Treg subtype deriving from effector $\mathrm{T}$ cells. J Autoimmun. 39, 377-387 (2012).

68. L. Halim, M. Romano, R. McGregor, I. Correa, P. Pavlidis, N. Grageda, S.J. Hoong, M. Yuksel, W. Jassem, R.F. Hannen, M. Ong, O. Mckinney, B. Hayee, S.N. Karagiannis, N. Powell, R.I. Lechler, E. Nova-Lamperti, G. Lombardi, An atlas of human regulatory T helper-like cells reveals features of Th2-like Tregs that support a tumorigenic environment. Cell Rep. 20, 757-770 (2017).

69. N. Komatsu, K. Okamoto, S. Sawa, T. Nakashima, M. Oh-hora, T. Kodama, S. Tanaka, J.A. Bluestone, H. Takayanagi, Pathogenic conversion of Foxp3+ T cells into TH17 cells in autoimmune arthritis. Nat Med. 20, 62-68 (2014).

70. M. Noval Rivas, O.T. Burton, P. Wise, L.M. Charbonnier, P. Georgiev, H.C. Oettgen, R. Rachid, T.A. Chatila, Regulatory $\mathrm{T}$ cell reprogramming toward a Th2-cell-like lineage impairs oral tolerance and promotes food allergy. Immunity 42, 12-523 (2015).

71. E. Ozcan, L.D. Notarangelo, R.S. Geha, Primary immune deficiencies with aberrant IgE production. J. Allergy Clin. Immunol. 122,1054-1062 (2008).

72. G.L. Cvetanovich, D.A. Hafler. Human regulatory T cells in autoimmune diseases. Curr. Opin. Immunol. 22,753-60 (2010).

73. M. Noval Rivas, T.A. Chatila, Regulatory T cells in allergic diseases. J. Allergy Clin. Immunol. 138, 639-652 (2016). 
74. Y. Ito, Y. Adachi, T. Makino, H. Higashiyama, T. Fuchizawa, T. Shimizu, T. Miyawaki, Expansion of FOXP3-positive $\mathrm{CD} 4^{+} \mathrm{CD} 25^{+} \mathrm{T}$ cells associated with disease activity in atopic dermatitis. Ann. Allergy Asthma Immunol. 103, 160-165(2009).

75. J.H. Lee, H.H. Yu, L.C. Wang, Y.H. Yang, Y.T. Lin, B.L. Chiang, The levels of $\mathrm{CD} 4{ }^{+} \mathrm{CD} 25^{+}$regulatory $\mathrm{T}$ cells in paediatric patients with allergic rhinitis and bronchial asthma. Clin. Exp. Immunol. 148, 53-63 (2007).

76. H.Z. Shi, S. Li, Z.F. Xie, X.J. Qin, X. Qin, X.N. Zhong, Regulatory CD4 $4^{+} \mathrm{CD} 25^{+} \mathrm{T}$ lymphocytes in peripheral blood from patients with atopic asthma. Clin. Immunol. 113, 172-178 (2004).

77. M. Akdis J. Verhagen, A. Taylor, F. Karamloo, C. Karagiannidis, R. Crameri, S. Thunberg, G. Deniz, R. Valenta, H. Fiebig, C. Kegel, R. Disch, C.B. Schmidt-Weber, K. Blaser, C.A. Akdis, Immune responses in healthy and allergic individuals are characterized by a fine balance between allergen-specific T regulatory 1 and T helper 2 cells. $J$. Exp. Med. 199, 1567-1575 (2004).

78. M.A. Curotto de Lafaille, N. Kutchukhidze, S. Shen, Y. Ding, H. Yee, J.J. Lafaille, Adaptive Foxp $3^{+}$regulatory $\mathrm{T}$ cell-dependent and -independent control of allergic inflammation. Immunity 29, 114-126 (2008).

79. J.T. Burchell, M.E. Wikstrom, P.A. Stumbles, P.D. Sly, D.J. Turner, Attenuation of allergen-induced airway hyperresponsiveness is mediated by airway regulatory $\mathrm{T}$ cells. Am. J. Physiol. Lung Cell. Mol. Physiol. 296, L307-L319 (2009).

80. A.M. Baru, V. Ganesh, J.K. Krishnaswamy, C. Hesse, C. Untucht, S. Glage, G. Behrens, C.T. Mayer, F. Puttur, T. Sparwasser, Absence of Foxp $3^{+}$regulatory T cells during allergen provocation does not exacerbate murine allergic airway inflammation. PLoS One 7, e47102 (2012).

81. D. Han, C. Wang, W. Lou, Y. Gu, Y. Wang, L. Zhang, Allergen-specific IL-10-secreting type I T regulatory cells, but not $\mathrm{CD} 4^{+} \mathrm{CD} 25^{+} \mathrm{Foxp} 3^{+} \mathrm{T}$ cells, are decreased in peripheral blood of patients with persistent allergic rhinitis. Clin. Immunol 136, 292-301(2010). 


\section{ACKNOWLEDGMENTS}

We thank N Rambabu and the staff of Centre d'Histologie, d'Imagerie et de Cytométrie, Centre de Recherche des Cordeliers for the help, A Fanidi for statistical advice, and Dr. V LanguillatFouquet and Pr. H Martelli, Service Chirurgie Pédiatrique, Hôpital Bicêtre, France for providing spleen sections of patients with spherocytosis.

\section{FUNDING}

Supported by the European Community's Seventh Framework Programme (FP7/2007-2013) under grant agreement HEALTH-2010.2.4.5-2 ALLFUN, Institut National de la Santé et de la Recherche Médicale (INSERM), Sorbonne Université and Université Paris Descartes. M.S., ESV. and A.K were recipient of fellowship from Indo-French Center for Promotion of Advanced Research (CEFIPRA) and CG. is a recipient of fellowship from La Fondation pour la Recherche Médicale (FDM20150633674), France.

\section{AUTHOR CONTRIBUTIONS}

M.S. and J.B. conceptualized the study. M.S., M.D., E.S-V. and J.B. designed the experiments. M.S., M.D., E.S-V., C.G., A.K. and M.S.M. performed the experiments. M.S., M.D., E.S-V., P.B., S.V.K. and J.B. analyzed and interpreted the data. M.S., M.D., E.S-V. and J.B. performed statistical analysis. P.B. provided essential tools. M.S. and J.B. wrote the manuscript and all authors edited and approved the manuscript.

\section{COMPETING INTERESTS}

The authors declare no competing financial interests

\section{DATA AND MATERIALS AVAILABILITY}

All data supporting the findings of this study are available within the article 


\section{Figure Legends}

Fig. 1. Human basophils are refractory to Treg-mediated suppression. Basophils were cultured either alone or with IL-3 or co-cultured with anti-CD3/anti-CD28-activated Tregs or Tconv cells in the presence of IL-3 at 1:3 ratio for 24 hours. During last one hour of the culture, basophils were stimulated with anti-IgE antibodies. (A-B) Representative plots and (C-H) mean \pm SEM of data from six independent experiments using cells from different donors showing the expression (mean fluorescence intensity, MFI and percent positive cells) of (C) CD203c, (D) CD13, (E, F) CD69, (G) CD63 and (H) CD107a on the basophils under various experimental conditions. (I) Amount of histamine released under above experimental conditions (mean \pm SEM, $\mathrm{n}=6) . * * \mathrm{P}<0.01 ; * * * \mathrm{P}<0.001 ; * * * * \mathrm{P}<0.0001 ; \mathrm{ns}$, not significant by one-way ANOVA with Tukey's multiple comparison test.

Fig. 2. Human basophils are unresponsive to contact-dependent or -independent inhibition by Tregs. (A, B) Expression of HLA-DR and co-stimulatory molecules CD80 and CD86 (mean \pm SEM, $\mathrm{n}=4$ donors) on resting and IL-3-stimulated basophils from human blood and spleen. (C, D) Percentage of Annexin V-and PI-positive basophils that were cultured for 24 hours in medium alone or with IL-3 or IL-3 plus anti-CD3/anti-CD28 activated Tregs or Tconv. Basophils were also stimulated with anti-IgE during last one-hour of the culture as indicated. Representative plots and mean \pm SEM of data from three independent experiments. (E) Expression of TGF- $\beta$ RII and IL-10R $\alpha$ (mean \pm SEM, $n=6$ donors) on human blood basophils. (F) Expression of CD123, CD13, CD69 and CD203c on IL-10R $\alpha^{+}$and IL-10R $\alpha^{-}$subsets of basophils (mean \pm SEM, $n=3$ independent experiments using cells from different donors) cultured for 24 hours with IL-3 and various concentrations of IL-10. During last one-hour culture, anti- 
IgE antibodies were added to stimulate basophils. ns; not significant by one-way ANOVA with Tukey's multiple comparison test (Panel D), two-way ANOVA with Least Significant Difference test (Panel F).

Fig. 3. Tregs induce activation of resting human basophils. Basophils were cultured for 24 hours either alone or co-cultured with anti-CD3/anti-CD28 activated Tregs or Tcnov. (A, B) Representative plots and mean \pm SEM of data from seven independent experiments using cells from different donors showing the expression of CD13, CD203c and CD69 on the basophils. (C, D) Representative dot plots and mean \pm SEM of data from five independent experiments showing the expression of degranulation markers CD63 and CD107a on the basophils. *P<0.05; $* * \mathrm{P}<0.01 ; * * * * \mathrm{P}<0.0001 ; \mathrm{ns}$, not significant by one-way ANOVA with Tukey's multiple comparison test.

Fig. 4. Induction of basophil cytokines by activated Tregs. Basophils were either cultured alone or with anti-CD3/anti-CD28 activated Tregs for 24 hours. Supernatants of co-cultures were analyzed for the amounts of $(\mathrm{pg} / \mathrm{ml}$, mean \pm SEM, $\mathrm{n}=6$ independent experiments using cells from different donors) (A) IL-13, (B) IL-8 and (C) IL-4. *P<0.05 by two-tailed paired Student's t-test.

Fig. 5. LFA-1-ICAM-1 interaction is dispensable for the Treg-induced human basophil activation. (A) Expression of ICAM-1 (mean \pm SEM, $n=5$ donors) on the resting and IL-3stimulated basophils. (B-D) Basophils were cultured for 24 hours either alone or co-cultured with anti-CD3/anti-CD28 activated Tregs with or without blocking MAbs to ICAM-1. (B, C) Representative plots indicating the expression of CD13, CD203c and CD69 on the basophils. (D) 
Histograms depicting the expression of CD13, CD203c and CD69 (mean \pm SEM, $n=4$ independent experiments using cells from different donors) on the basophils. (E) Expression of CD13, CD203c and CD69 (mean \pm SEM, $n=5$ independent experiments using cells from different donors) on the basophils co-cultured with Tregs either in direct contact or in transwells. ${ }^{*} \mathrm{P}<0.05$; **P $<0.01 ; * * * \mathrm{P}<0.001 ; * * * * \mathrm{P}<0.0001 ;$ ns, not significant by one-way ANOVA with Tukey's multiple comparison test.

Fig. 6. Soluble mediators released from activated Tregs stimulate basophils. Basophils were cultured for 24 hours either alone or with cell-free culture supernatants (SUP) from unstimulated (U-Tregs) or anti-CD3/anti-CD28-stimualted Tregs (S-Tregs). (A, B) The level of expression of (MFI or percent positive cells) (A) CD13, CD203c, CD69, and (B) degranulation markers CD63 and CD107a on the basophils (mean \pm SEM, $n=3$ independent experiments using cells from different donors). ${ }^{*} \mathrm{P}<0.05 ; * * \mathrm{P}<0.01$; ns, not significant by one-way ANOVA with Tukey's multiple comparison test.

Fig. 7. Tregs induce human basophil activation by an IL-3-dependent mechanism. Basophils were cultured for 24 hours either alone or co-cultured with anti-CD3/anti-CD28 stimulated Tregs in the presence of isotype control MAbs or blocking MAbs to IL-3R. (A) Representative plots of CD13, CD203c, CD69 and FceRI expression on basophils. (B) Histograms (mean \pm SEM) depicting the expression of CD13 ( $n=8$ independent experiments using cells from different donors), CD203c, FceRI and CD69 ( $\mathrm{n}=11$ independent experiments) on the basophils. (C) Amounts of secretion of IL-13 and IL-8 (mean \pm SEM, n=5 independent 
experiments using cells from different donors) by basophils. $* \mathrm{P}<0.05 ; * * \mathrm{P}<0.01 ; * * * \mathrm{P}<0.001$; $* * * * \mathrm{P}<0.0001$ by one-way ANOVA with Tukey's multiple comparison test.

Fig. 8. Tregs induce activation of basophils by STAT5 pathway. (A, B) Basophils were cultured for 6 hours either alone or with IL-3 or co-cultured with anti-CD3/anti-CD28-stimulated Tregs. (A) Representative plots of pSTAT5 expression in basophils and (B) mean \pm SEM of pSTAT5-positive basophils from four independent experiments using cells from different donors. (C, D) Basophils were pre-treated with STAT5 inhibitor (STAT5 inh) or DMSO followed by co-culture with Tregs for 24 hours. (C) Expression of CD13, CD203c, and CD69 on the basophils, and (D) the amounts of IL-13 and IL-8 in the culture supernatants (mean \pm SEM, $\mathrm{n}=4$ independent experiments). $\mathrm{ns}$, not significant; $* \mathrm{P}<0.05 ; * * \mathrm{P}<0.01 ; * * * * \mathrm{P}<0.0001$ by oneway ANOVA with Tukey’s multiple comparison test. 
Figure 1
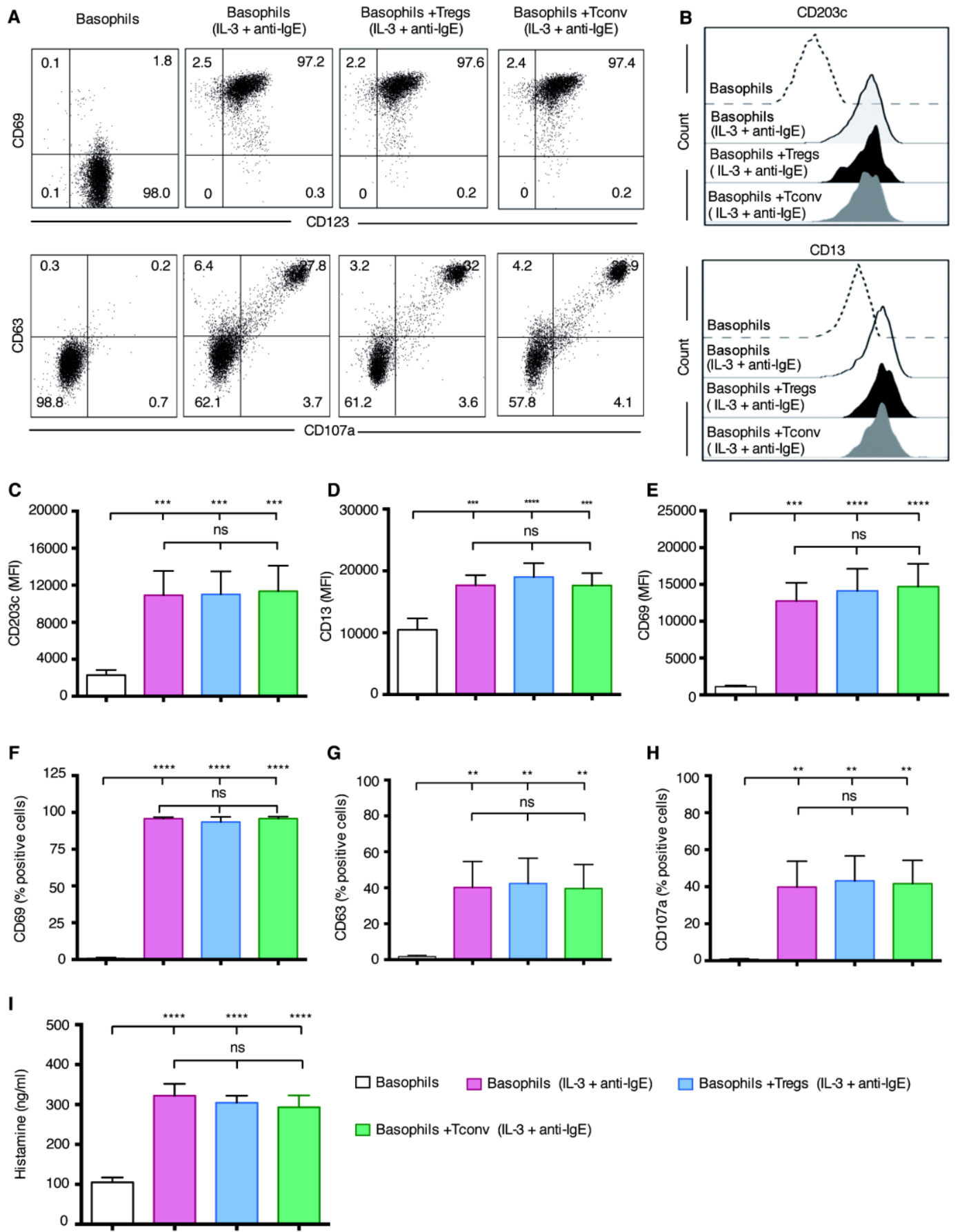

$\square$ Basophils $\square$ Basophils (IL-3 + anti-lgE) $\square$ Basophils + Tregs (IL-3 + anti-lgE)

$\square$ Basophils +Tconv (IL-3 + anti-lgE) 
Figure 2

A

Resting basophils
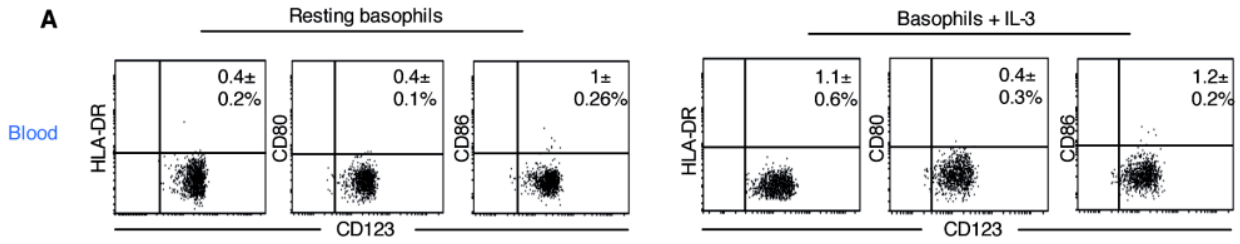

B
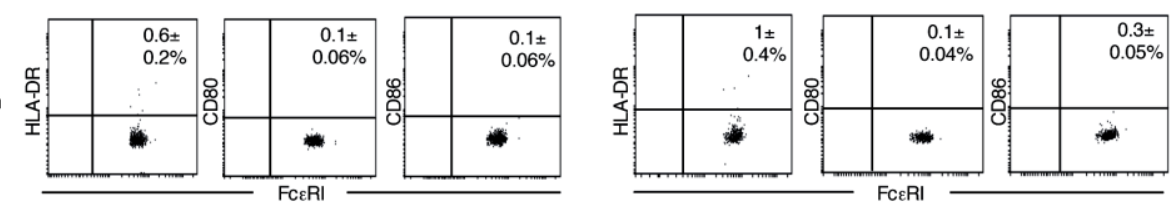

C
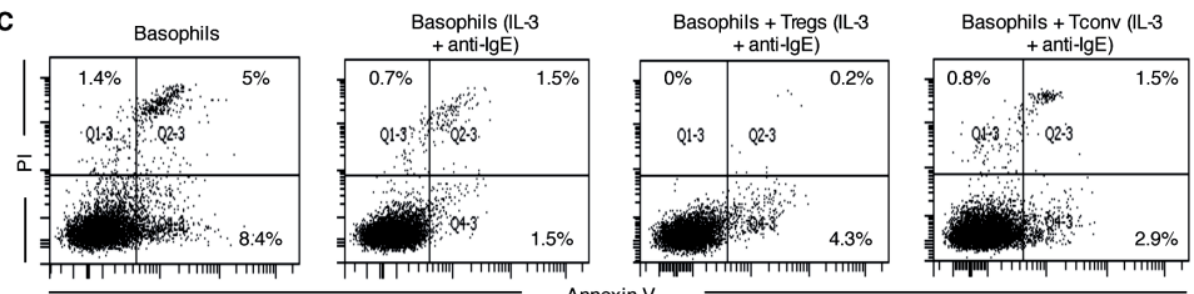

D

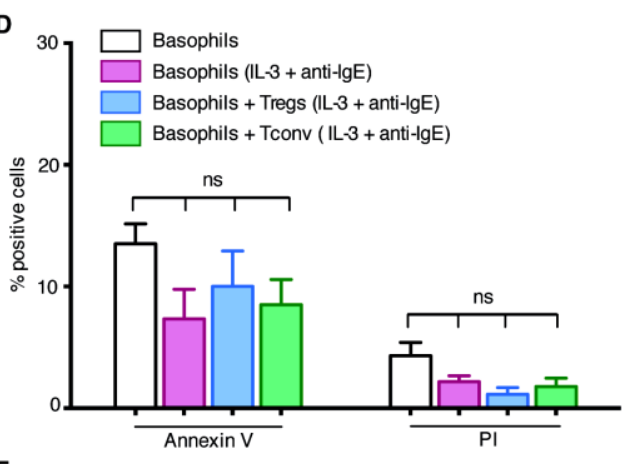

E

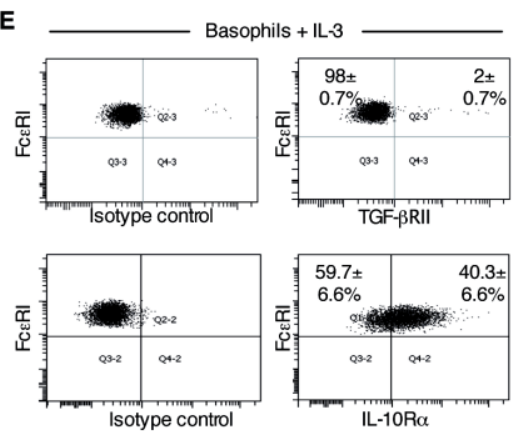

F
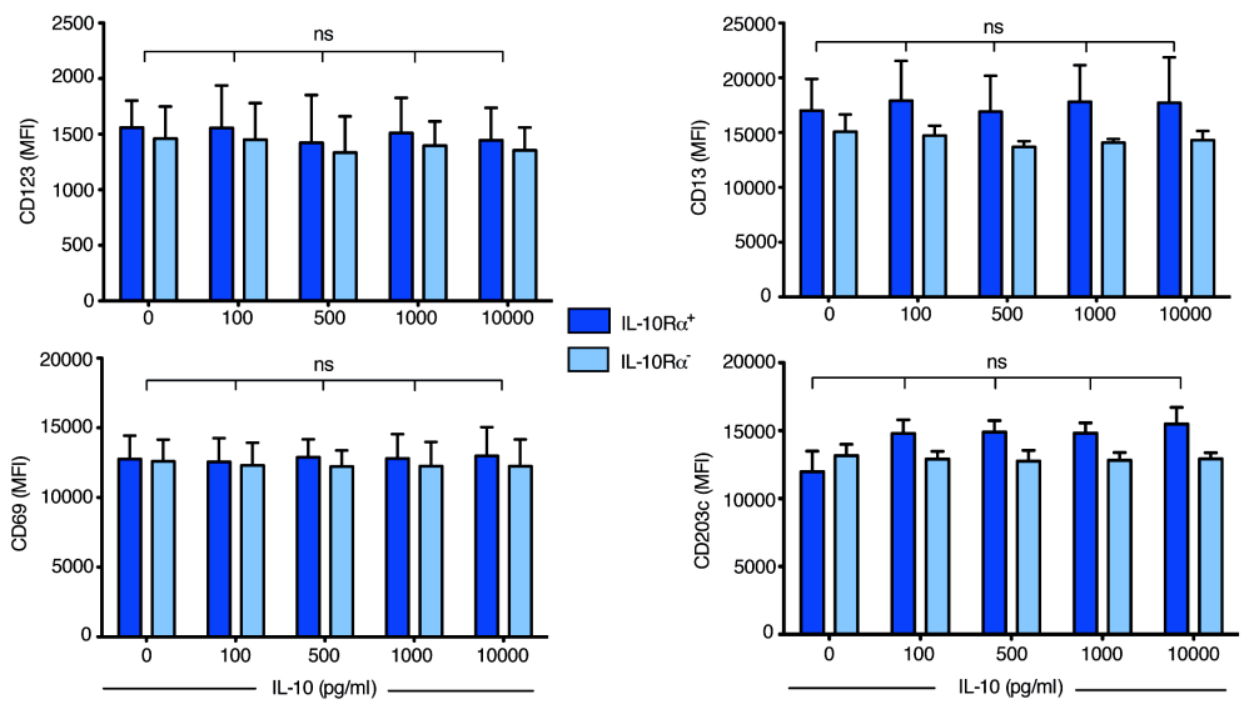
Figure 3

A

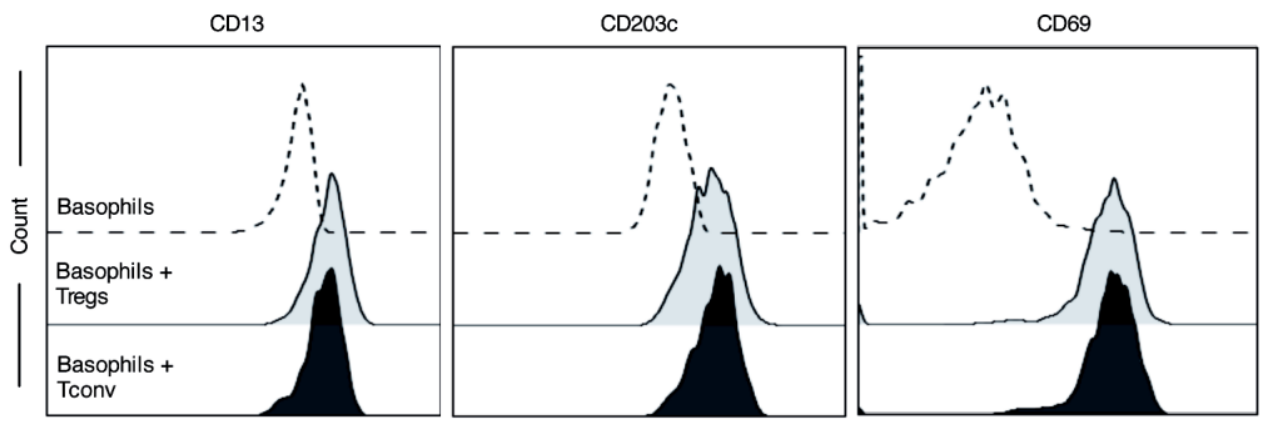

B
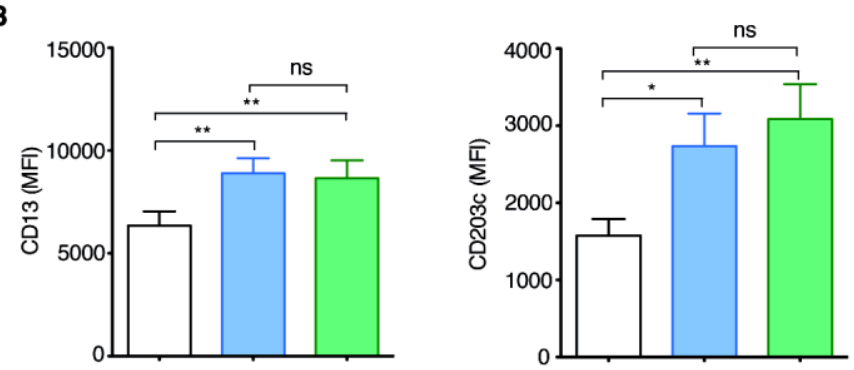

C
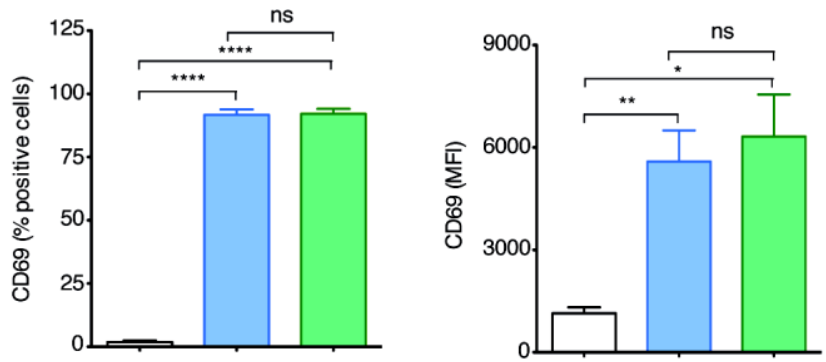

D
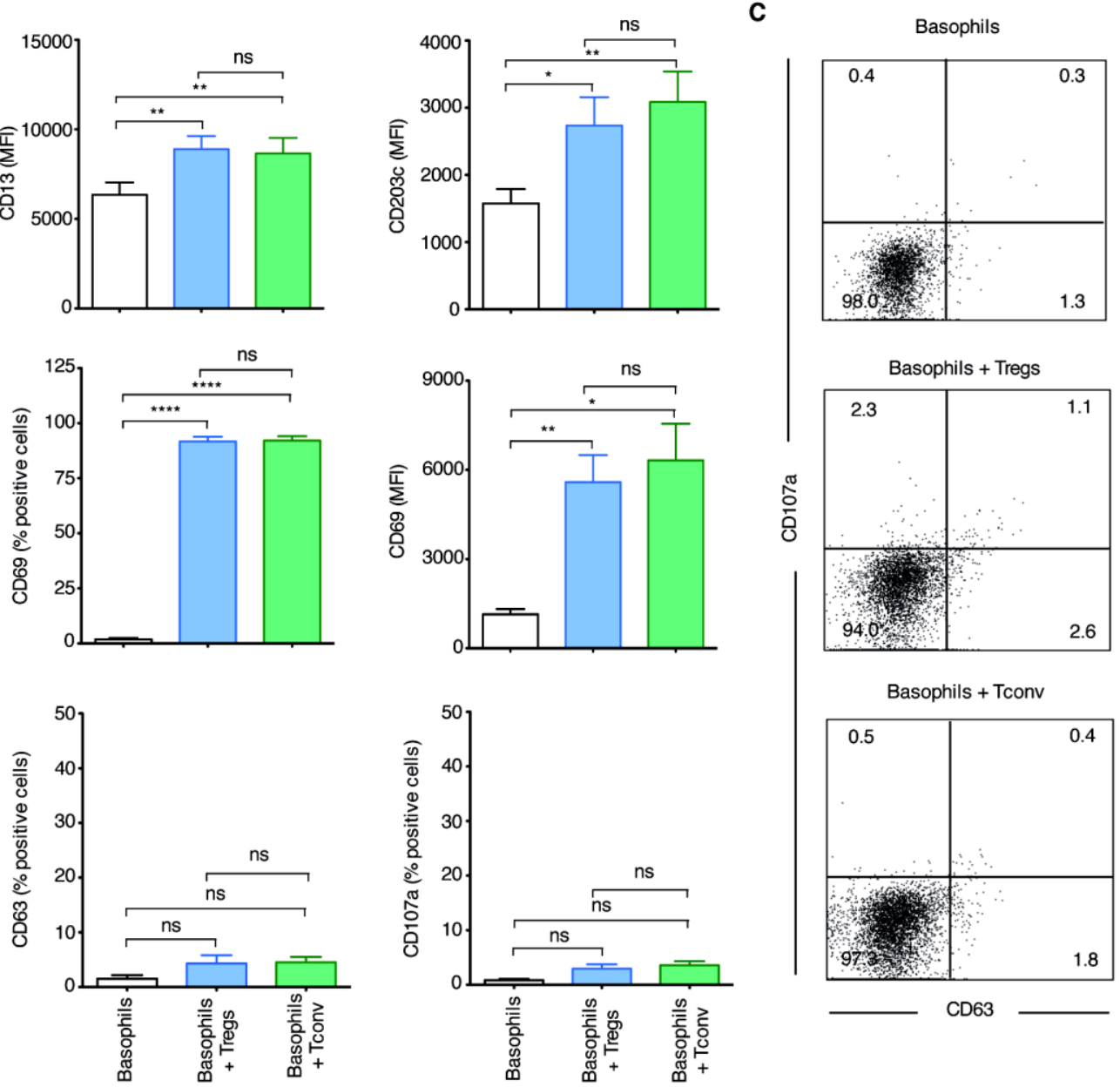
Figure 4

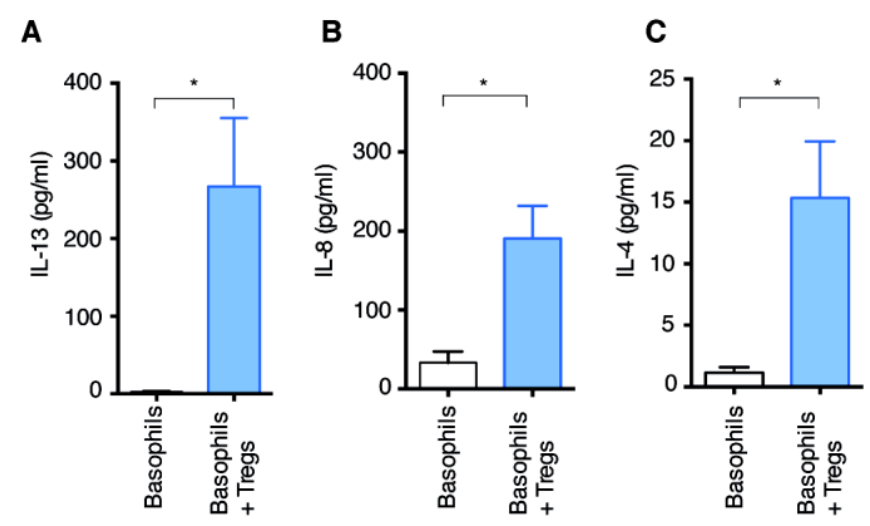


Figure 5
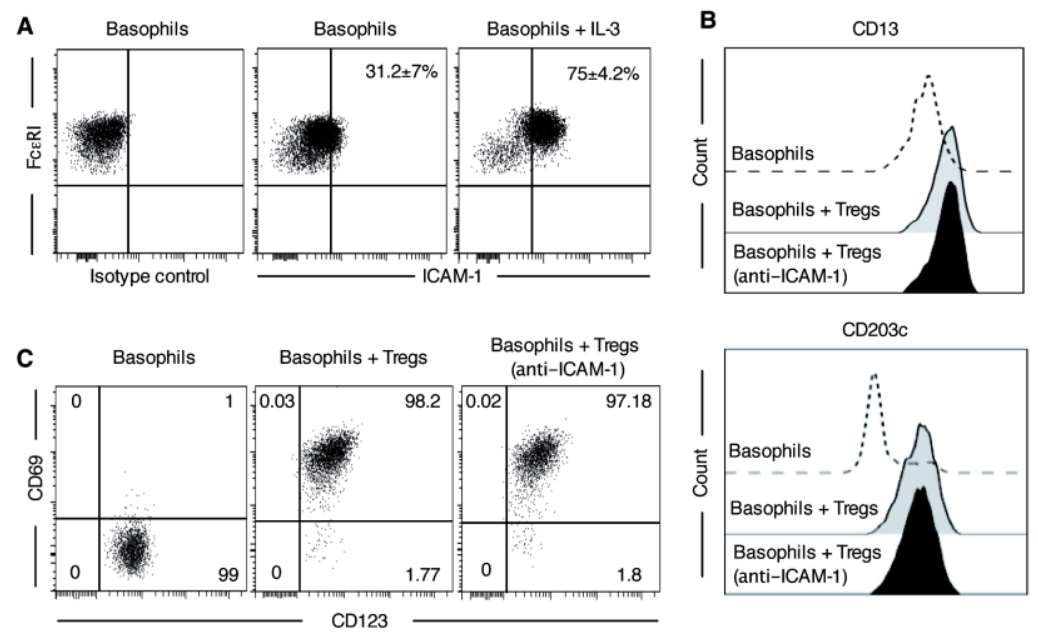
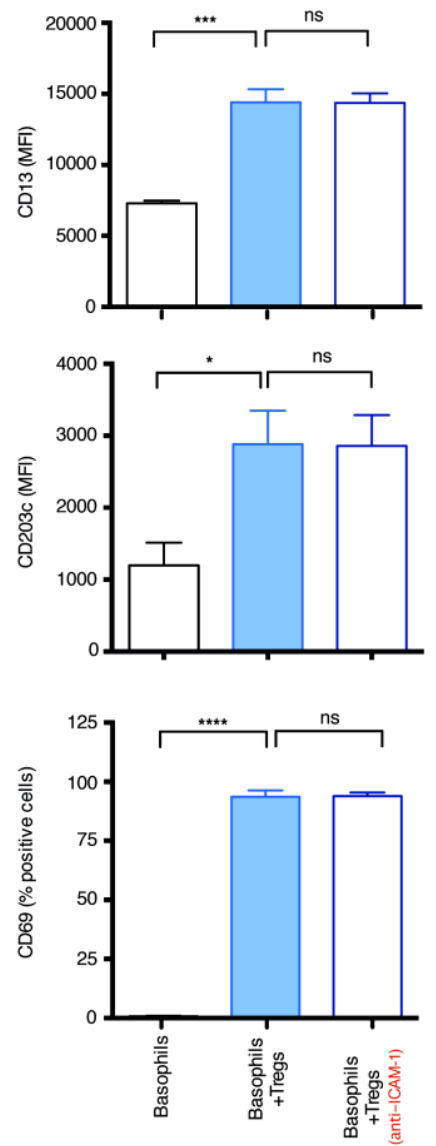
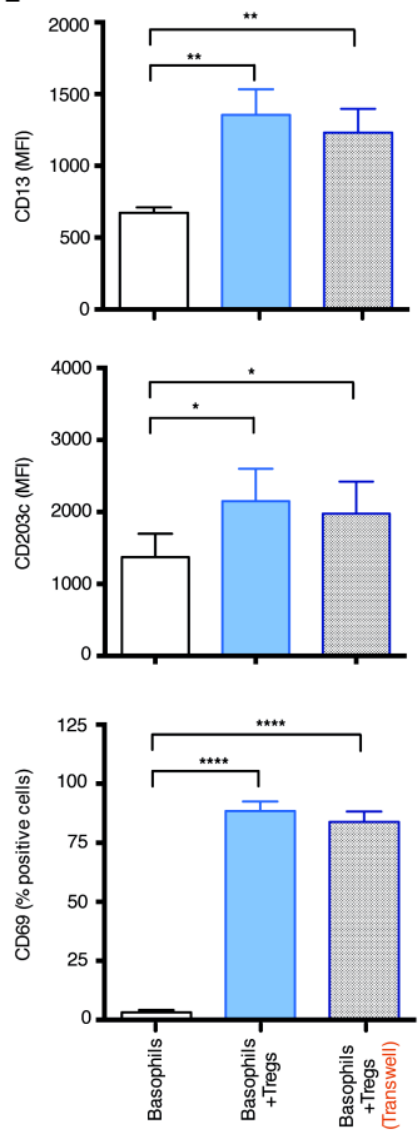
Figure 6
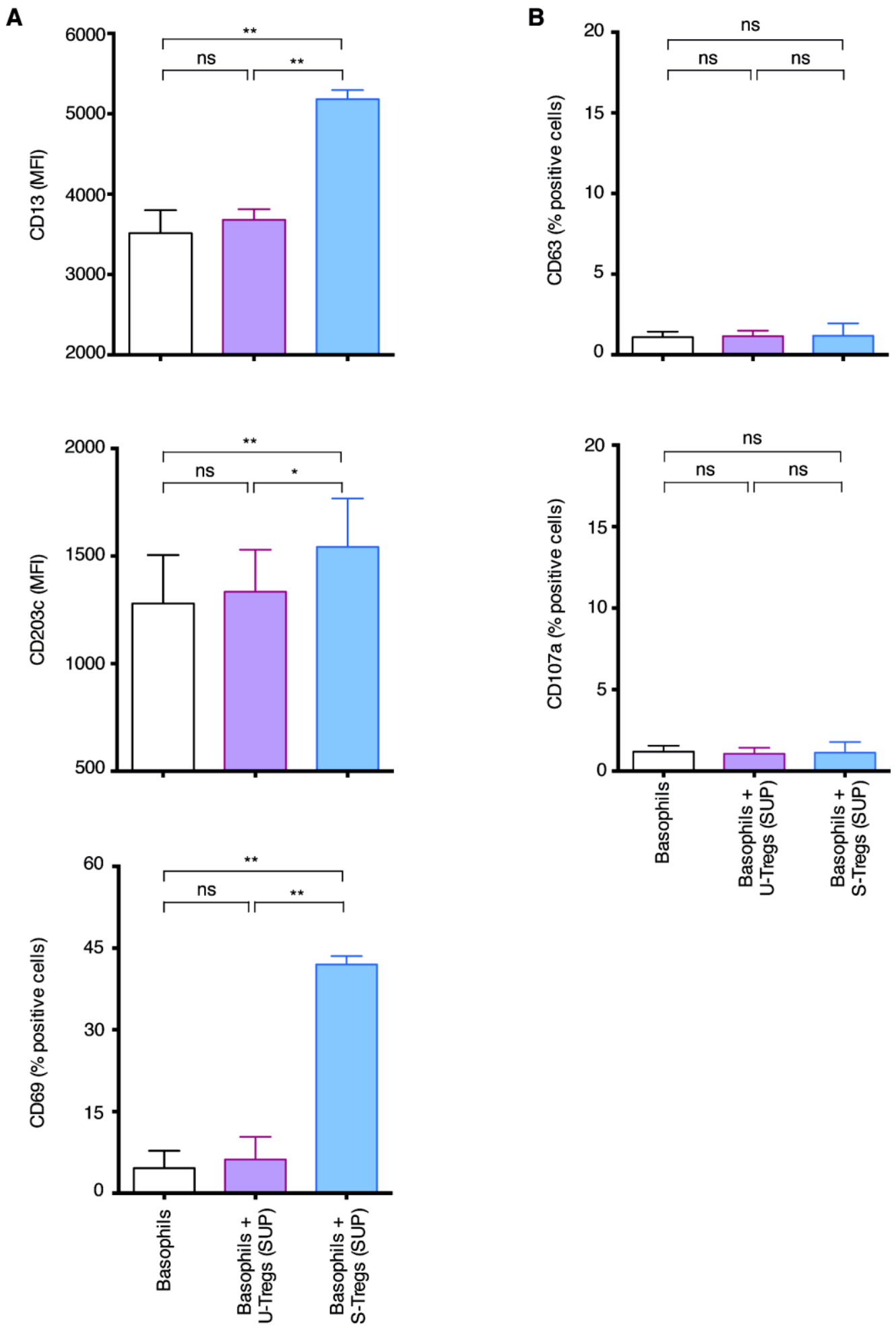
Figure 7

A

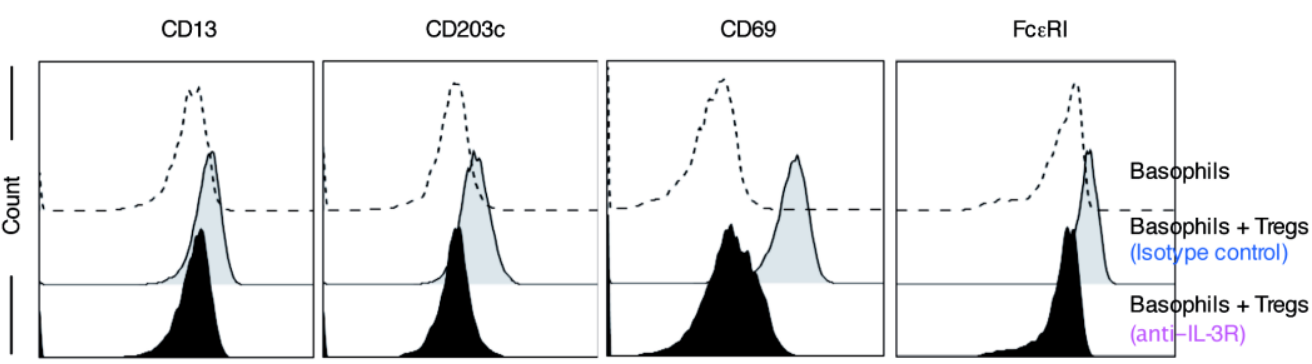

B
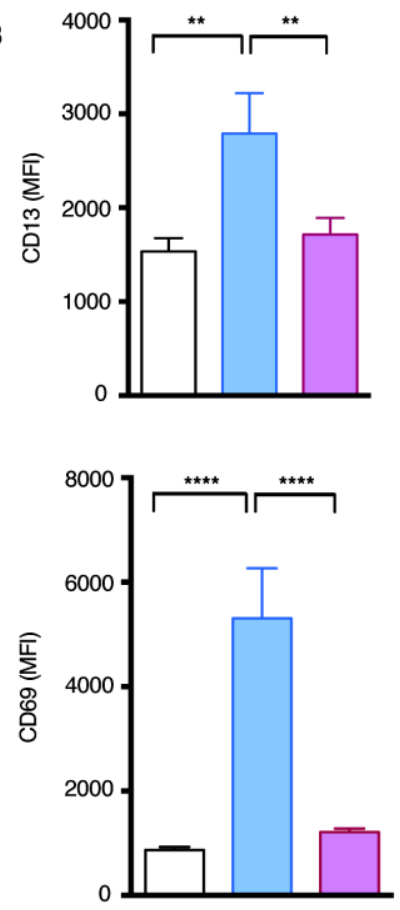

C

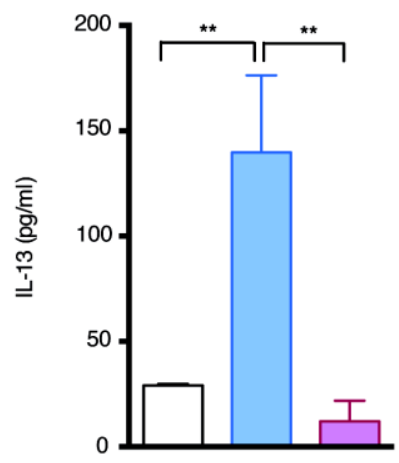

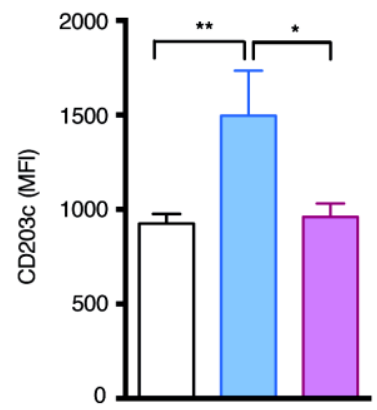
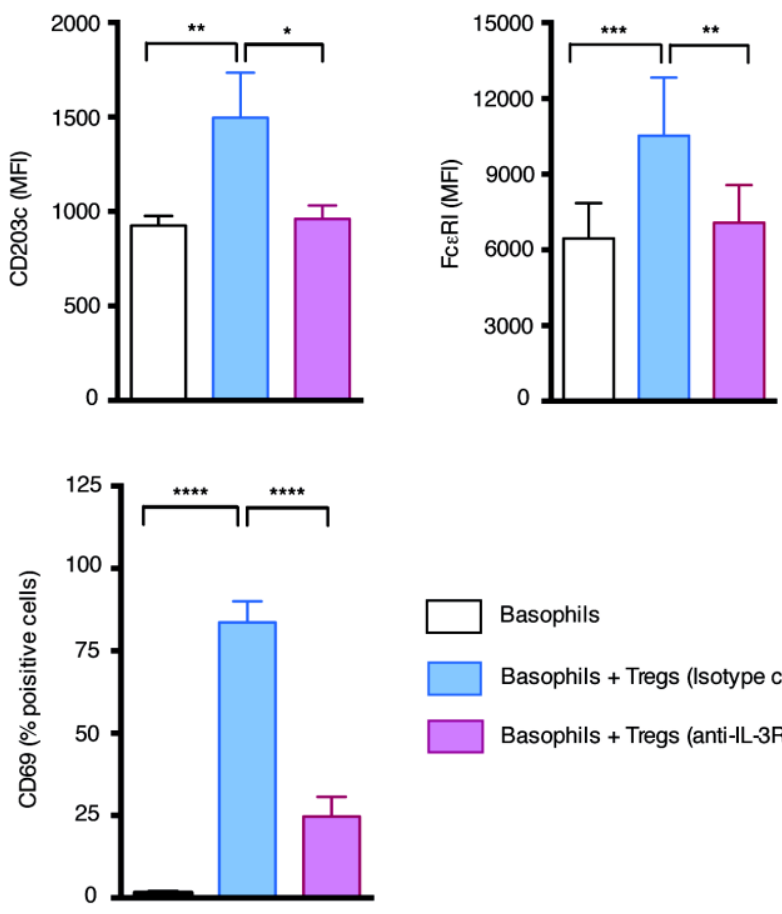

Basophils

Basophils + Tregs (Isotype control)

Basophils + Tregs (anti-IL-3R)

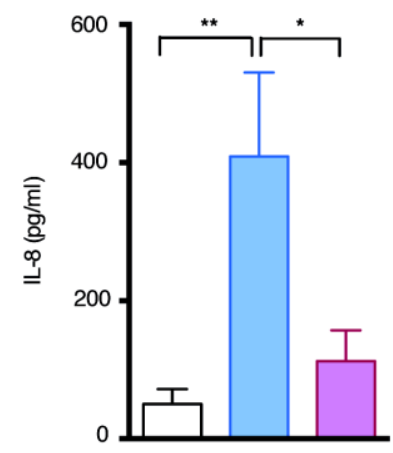


Figure 8

A

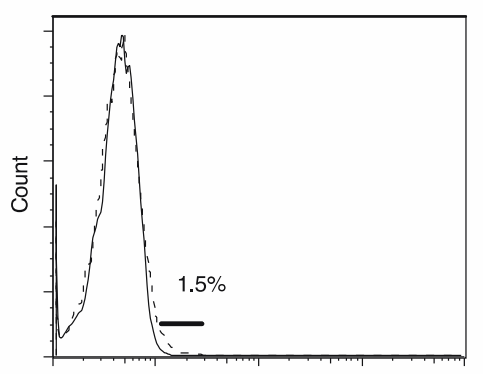

Basophils + IL-3

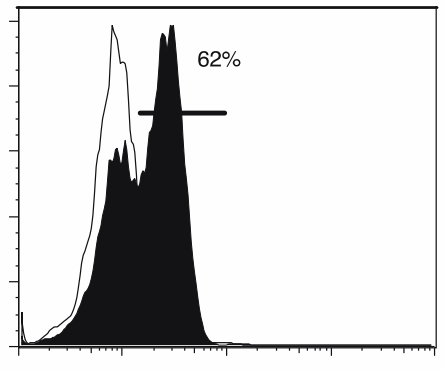

pSTAT5
Basophils + Tregs

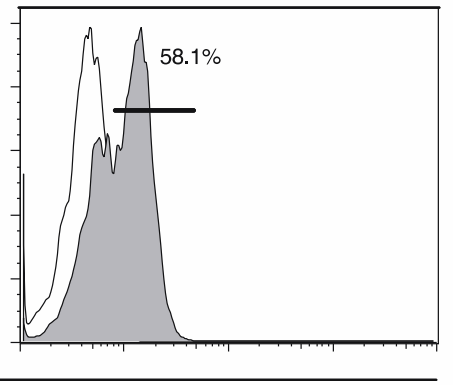

B

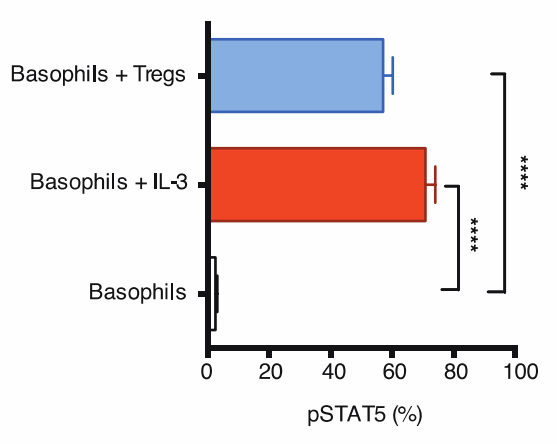

C
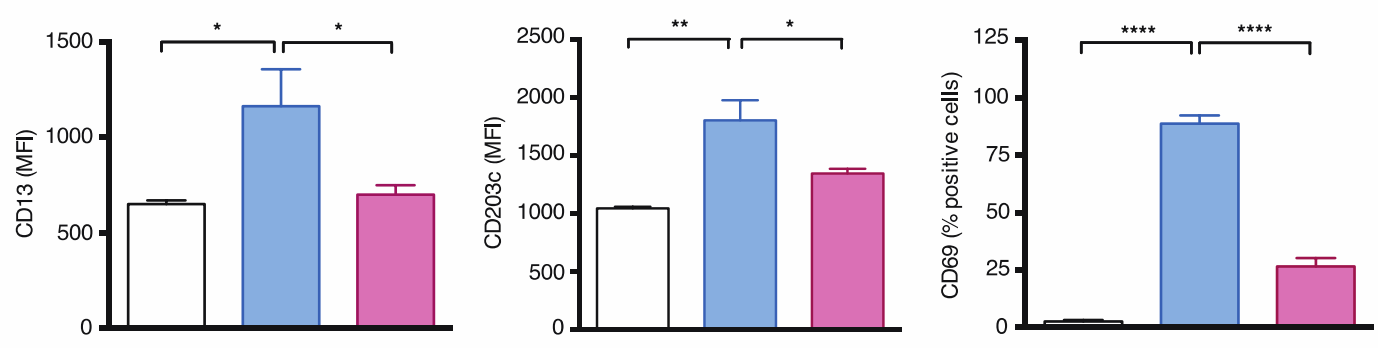

D

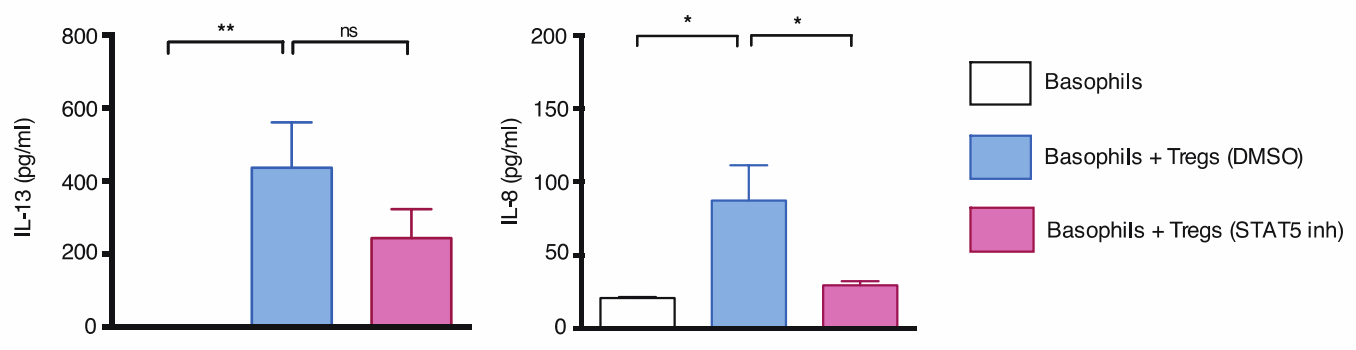




\section{SUPPLEMENTARY FILE}

\section{MATERIALS AND METHODS}

\section{Antibodies}

The following antibodies were used in the work.

BD Biosciences: CD4-Alexa700, CD4-BV421 (Clone: RPA-T4), HLA-DR-FITC, HLA-DRAPC (Clone: TU36), CD86-FITC (Clone: FUN-1), CD80-PE (Clone: L307.4), CD54-PE (Clone: HA58), CD63-PE (Clone: H5C6), CD25-FITC (Clone: M-A251), CD13-APC (Clone: WM15), CD275-PE (clone 2D3/B7-H2) CD123-BV421 (Clone: 9F5), CD127-PE (clone HIL-7R-M21), CD203c-PE (Clone: NP4D6), CD117/c-kit-PerCP-Cy5.5 (Clone: YB5.B8), CD69-APC/Cy, CD69-PE (Clone: FN50), CD127-BV421 (Clone: HIL-7R-M21), CD45RO-PE, CD45RO-FITC (Clone: UCHL1), CD45RA-FITC, CD45RA-APC (Clone: HI100) MAbs, pSTAT5 (pY694) Alexa Fluor® 488 (Clone 47/Stat5(pY694)), and Annexin V-APC.

Miltenyi Biotec: BDCA-1 (CD1c)-APC (Clone: AD5-8E7), BDCA-2 (CD303)-APC (Clone: AC144), BDCA-3 (CD141)-APC (Clone: AD5-14H2), BDCA-4 (CD304)-APC (Clone: AD517F6), CD123-VioBlue, CD123-APC (Clone: AC145) and FceRIa-FITC (Clone: CRA-1) MAbs. R\&D systems: Anti-CD3 MAb (Clone: UCHT1), anti-CD28 MAb (clone 37407), TGF- $\beta$ RIIFITC MAb (Clone: 25508), blocking MAbs to ICOSL (Clone 136726), ICAM-1 (Clone 11C81) and IL-3R $\alpha$ (Clone: 32703), and IL-10R $\alpha$-PE goat IgG.

eBioscience: FoxP3-APC (Clone: 236A/E7), Fixable Vibility Dye eFluor 506 and CD107aeFluor 660 (Clone: eBioH4A3).

BioLegand: FceRIa-BV510 (Clone: AER37 (CRA-1)), CD107a-BV421 (Clone: H4A3), CD13APC/Cy7 (Clone: WM15), CD203c-BV421 and CD203c-PE (Clone: NP4D6) MAbs.

Sigma-Aldrich: Polyclonal affinity isolated anti-human $\operatorname{IgE}(\varepsilon$-chain specific) antibody

Various isotype control MAbs were from R\&D systems, eBioscience or BD Biosciences.

\section{Buffy bags of healthy donors}

Buffy bags of healthy donors were obtained from Centre Necker-Cabanel, Etablissement Français du Sang, Paris. Ethical committee permission was obtained for the use of buffy bags of healthy donors (Institut National de la Santé et de la Recherche-EFS ethical committee convention 15/EFS/012). Buffy bags were subjected to Ficoll density gradient centrifugation and cellular fractions containing peripheral blood mononuclear cells (PBMCs) and basophils were collected.

\section{Human spleen samples}

Samples of human spleen from healthy individuals, untreated subjects presented for pathological investigations or patients with spherocytosis were obtained from Service d'Anatomie Pathologique, Hôpital Européen Georges Pompidou, Paris, France and Service de Chirurgie Viscérale Pédiatrique, Hôpital Bicêtre, Kremlin Bicêtre. For our work, only healthy tissues (noninvaded) were used. 


\section{Flow cytometry}

The surface and intracellular staining of basophils, DCs and T cells was performed using fluorochrome-conjugated MAbs at pre-determined concentrations. Cell Signaling Buffer Set A was used to analyze phosphorylation status of STAT5 in basophils. Intracellular staining of $\mathrm{CD}^{+} \mathrm{T}$ cells was performed by using Fixation/Permeabilization reagents from eBioscience. The samples were acquired using LSR II (BD Biosciences) and data were analyzed by BD FACS DIVA (BD Biosciences) and Flowjo (FlowJo LLC) programs. 

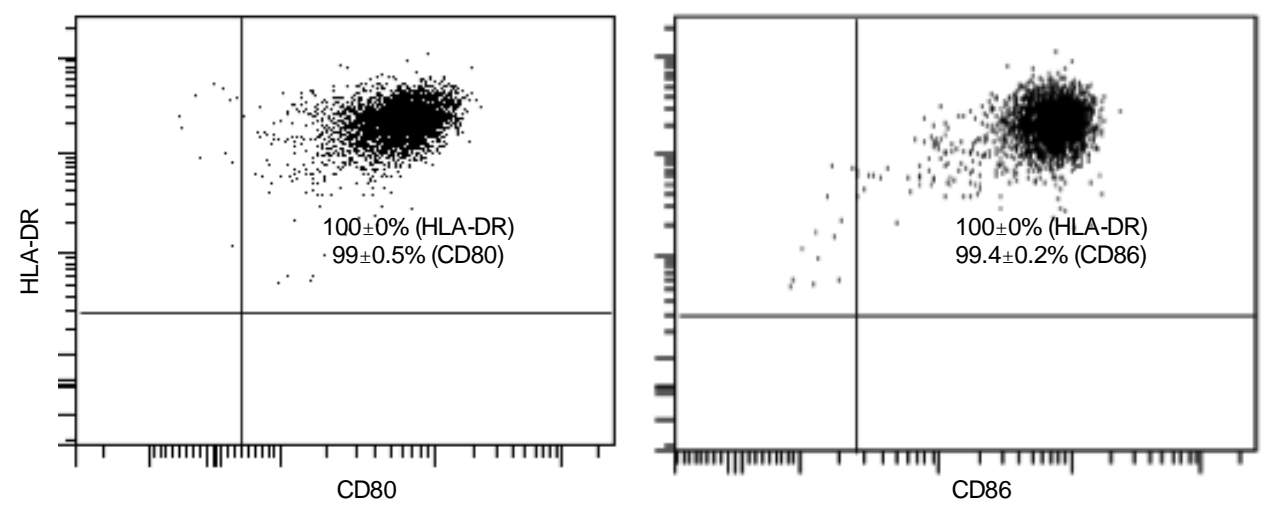

Fig. S1. Expression of HLA-DR, CD80 and CD86 on human dendritic cells. Monocytederived DCs were stimulated with lipopolysaccharide $\left(10 \mathrm{ng} / 0.5 \times 10^{6}\right.$ cells $)$ for 24 hours and analyzed for the expression of HLA-DR, CD80 and CD86 (mean \pm SEM, n=5 donors). 


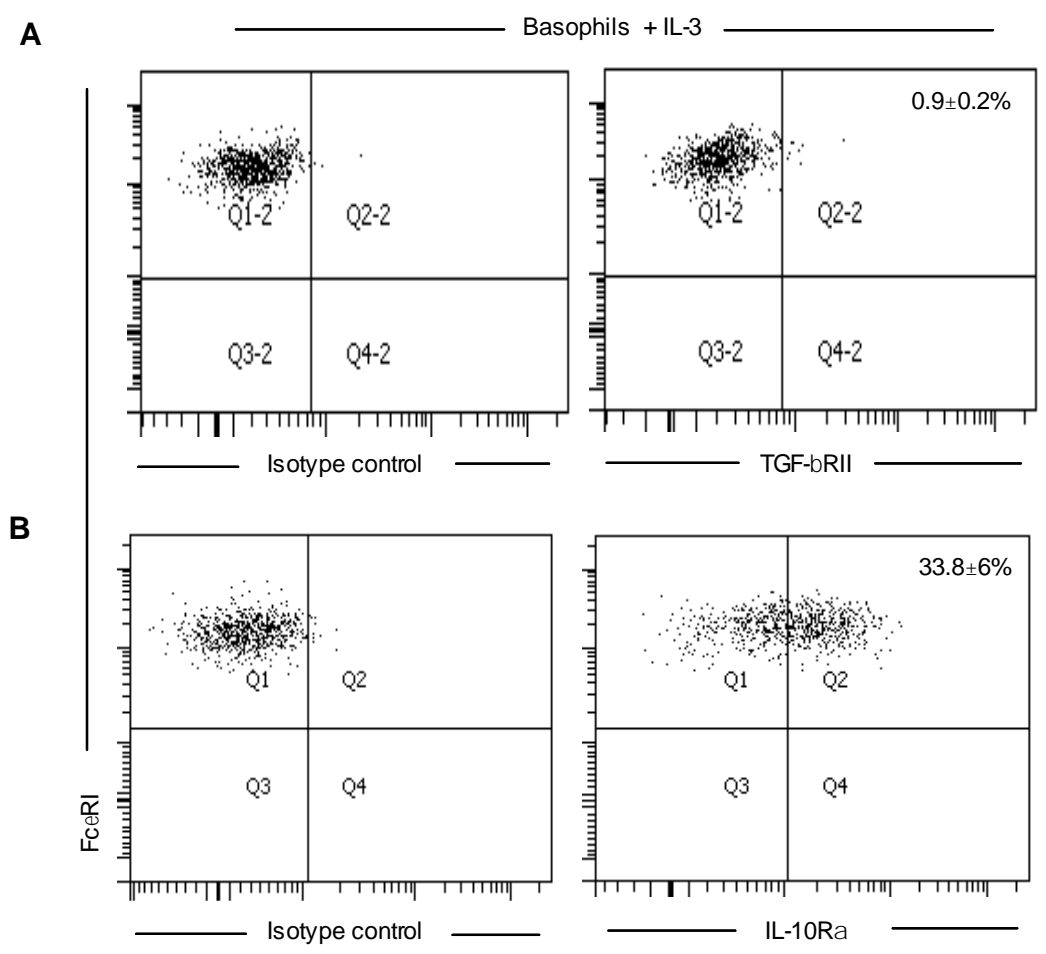

Fig. S2. Expression of TGF- $\beta$ RII and IL-10R $\alpha$ on human splenic basophils. Representative plots depicting the expression of (A) TGF- $\beta$ RII and (B) IL-10R $\alpha$ on IL-3-stimulated human splenic basophils. Isotype control antibody staining was shown in left panels. Values presented are mean \pm SEM from the spleen of six donors. 

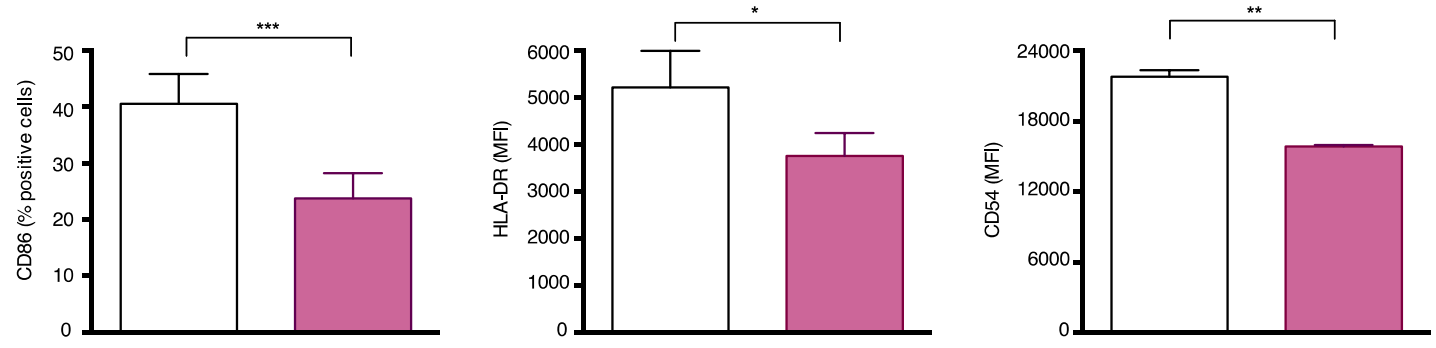

DC Ctr $\square$ DC - IL-10

Fig. S3. Effect of IL-10 on the phenotype of human dendritic cells. Monocyte-derived DCs were either cultured alone (DC Ctr) or treated with IL-10 (10 ng/0.5x10 cells) for 24 hours. Expression of CD86, HLA-DR and CD54 was analyzed (mean \pm SEM, $\mathrm{n}=4$ independent donors). $* \mathrm{P}<0.05 ; * * \mathrm{P}<0.01 ; * * * \mathrm{P}<0.001$ by two-tailed paired Student's t-test. 

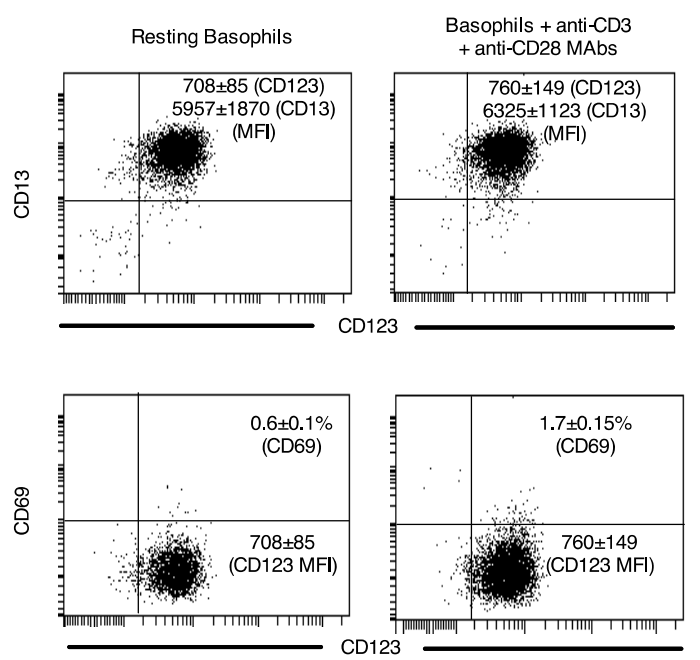
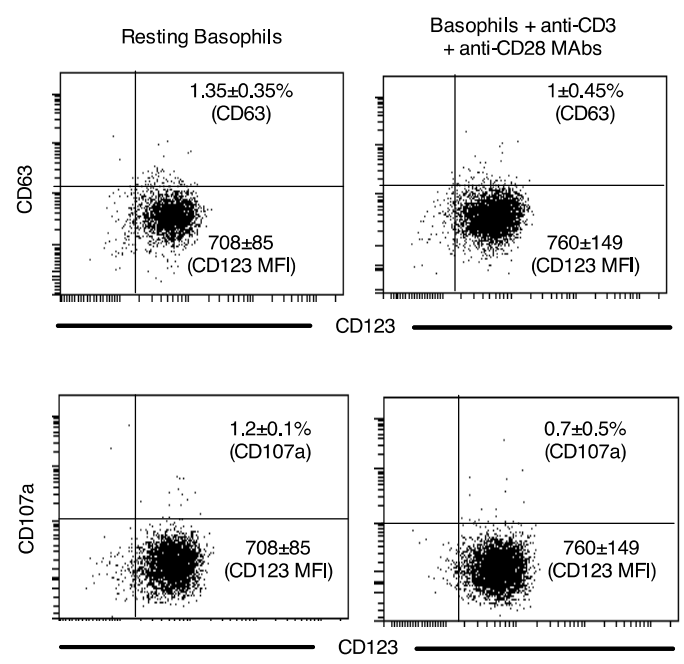

Fig. S4. Anti-CD3 and anti-CD28 MAbs do not alter the phenotype of basophils. Human basophils were either cultured alone or in the presence of plate-bound anti-CD3 MAb (1 $\mu \mathrm{g} / \mathrm{ml})$ and soluble anti-CD28 MAb $(1 \mu \mathrm{g} / \mathrm{ml})$ for 24 hours. The expression of indicated markers on the basophils was analyzed by flow cytometry. The data (mean \pm SEM) are from two independent experiments using cells from different donors. 

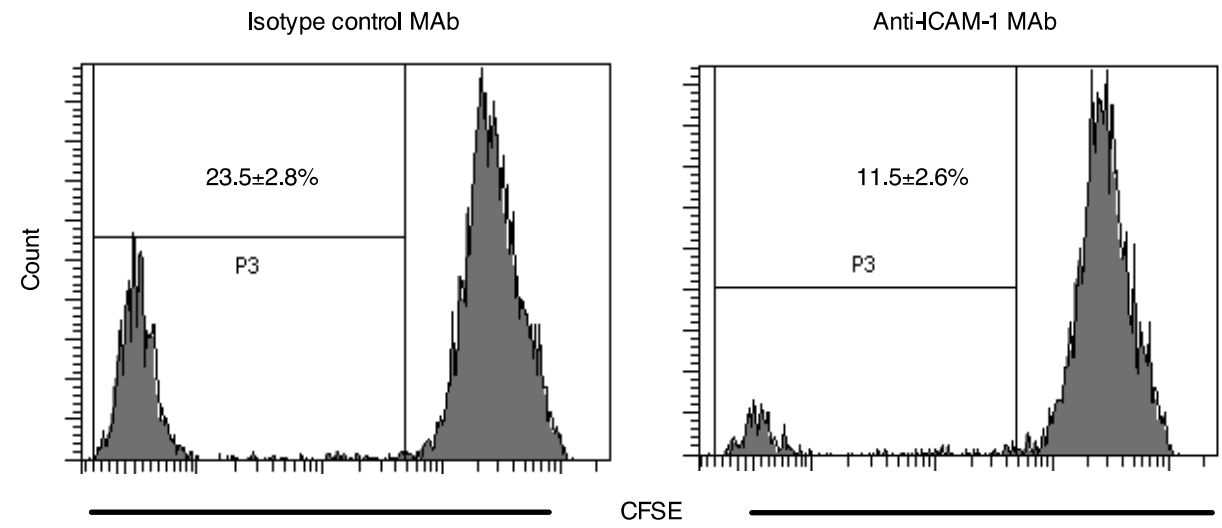

Fig. S5. Blocking of ICAM-1 on dendritic cells inhibits dendritic cell-mediated $\mathrm{CD4}^{+} \mathrm{T}$ cell proliferation. DCs were pre-incubated with blocking MAb to ICAM-1 $(20 \mu \mathrm{g} / \mathrm{ml})$ or isotype control MAb for 2 hours followed by co-culture with CFSE-labelled allogeneic $\mathrm{CD}^{+} \mathrm{T}$ cells $\left(0.1 \times 10^{6}\right.$ cells/well $)$ at $1: 20$ ratio in a total volume of $200 \mu \mathrm{L}$ for five days. Proliferation of $\mathrm{CD}^{+}$ $\mathrm{T}$ cells was analyzed based on the dilution of CFSE. The data (mean \pm SEM) are from two independent experiments using cells from different donors. 
A

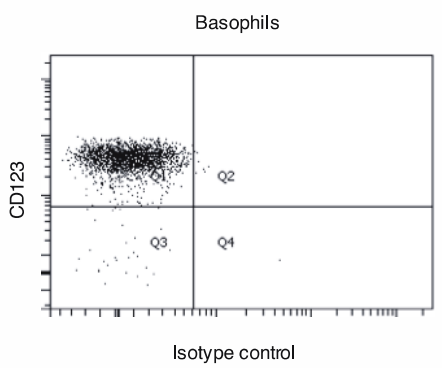

B

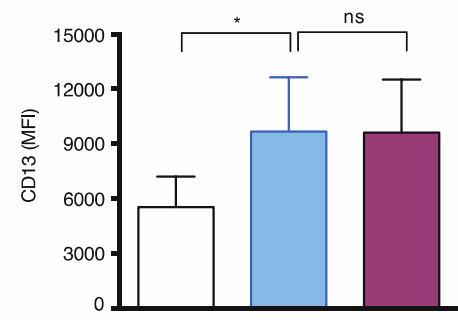

Basophils
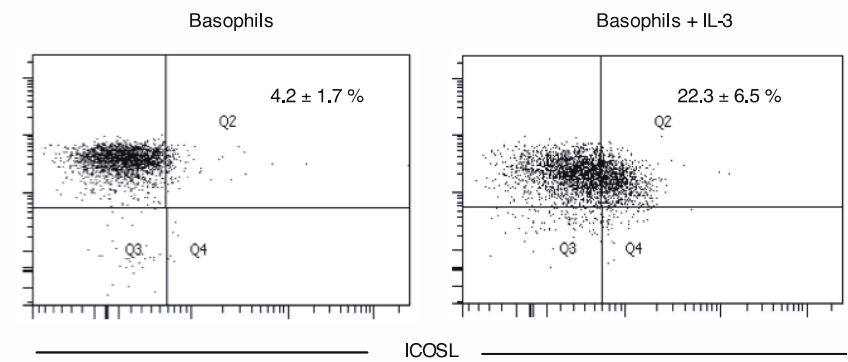

ICOSL

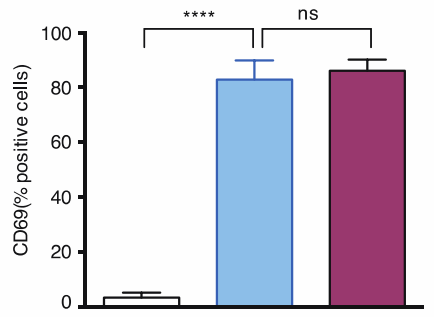

Basophils + Tregs (anti-ICOSL)

Fig. S6. ICOS-ICOSL interaction is dispensable for the Treg-mediated human basophil activation. (A) The expression of ICOSL (mean \pm SEM, $n=5$ donors) on resting and IL-3stimulated basophils. (B) Basophils $\left(0.1 \times 10^{6}\right.$ cells $\left./ 200 \mu \mathrm{L}\right)$ were cultured for 24 hours either alone or co-cultured with anti-CD3/anti-CD28 activated Tregs with or without blocking MAbs to ICOSL $(10 \mu \mathrm{g} / \mathrm{ml})$. The expressions (mean \pm SEM, $\mathrm{n}=5$ independent experiments using cells from different donors) of $\mathrm{CD} 13, \mathrm{CD} 203 \mathrm{c}$ and CD69 on the basophils are depicted. $* \mathrm{P}<0.05$; $* * \mathrm{P}<0.01 ; * * * * \mathrm{P}<0.0001 ;$ ns, not significant by one-way ANOVA with Tukey's multiple comparison test. 


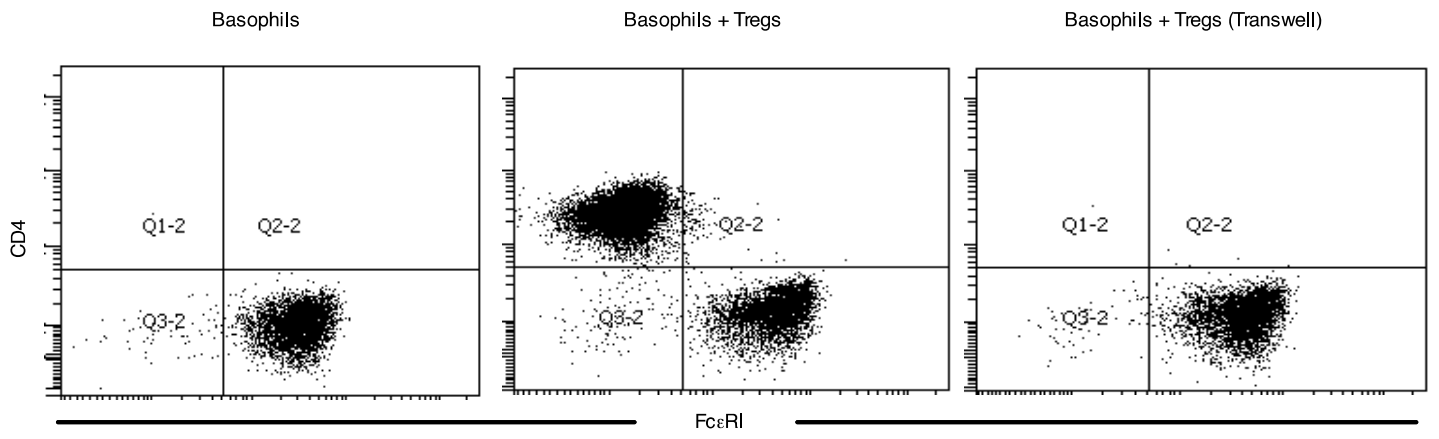

Fig. S7. Representative dot-plots depicting the absence of $\mathrm{CD4}^{+} \mathrm{T}$ cells in the lower chambers of tranwells. Basophils were cultured either alone or co-cultured with Tregs in direct contact or in transwells for 24 hours followed by analysis of cells (basophils and CD ${ }^{+} \mathrm{T}^{-}$cells) in the lower chambers based on the expression of FceRI and CD4. 


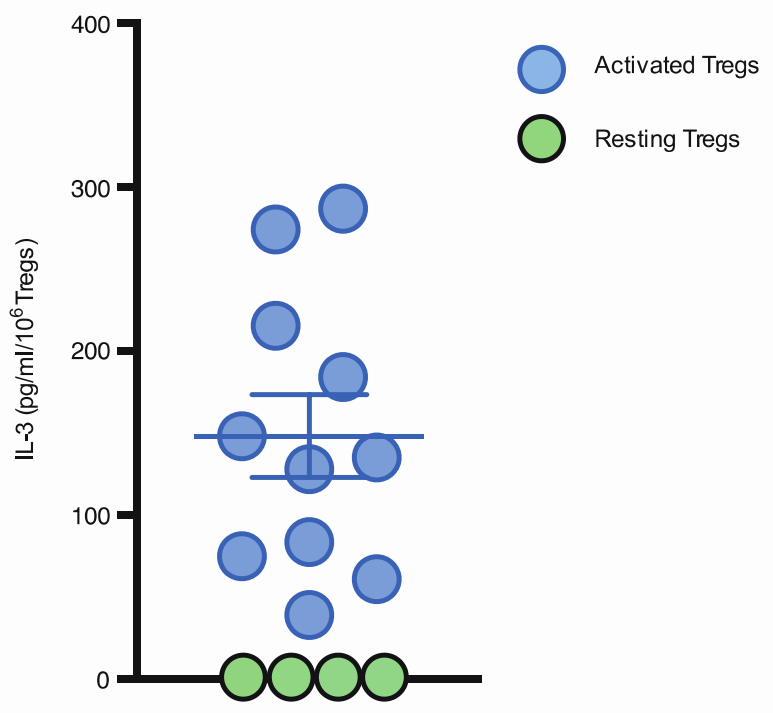

Fig. S8. IL-3 secretion by human Tregs. Level of IL-3 (pg/ml/10 6 Tregs, mean \pm SEM) released from the anti-CD3 and anti-CD28-activated Tregs ( $\mathrm{n}=11$ donors) or resting Tregs $(\mathrm{n}=4$ donors). 

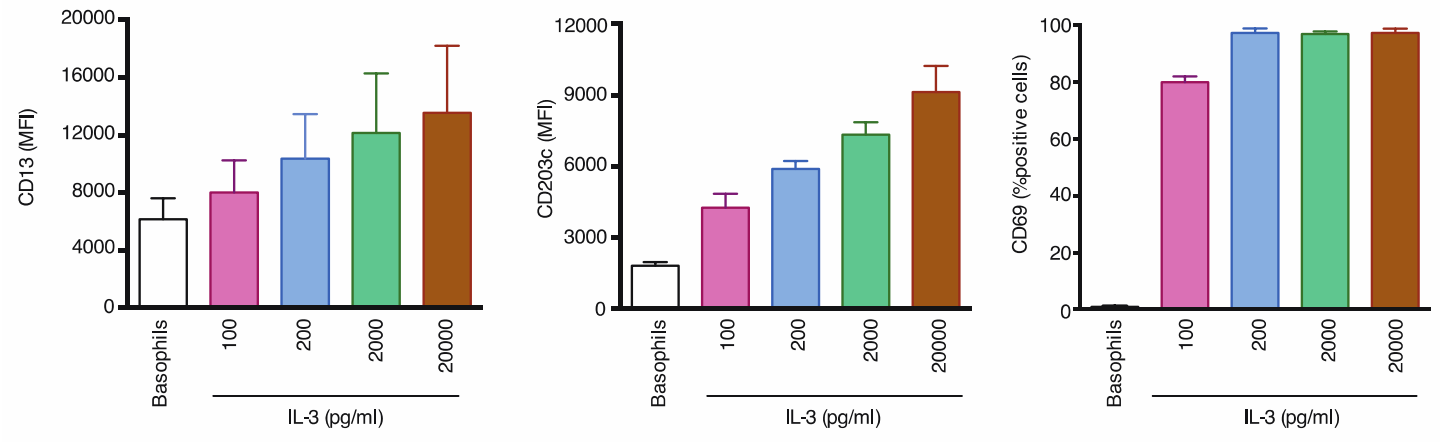

Fig. S9. Dose-dependent effects of IL-3 on the phenotype of human basophils. Basophils $\left(0.1 \times 10^{6}\right.$ cells) were cultured for 24 hours either alone or with various doses of IL-3 (100-20000 $\mathrm{pg} / \mathrm{ml}$ ) for 24 hours. The expression of CD13, CD203c and CD69 (mean \pm SEM, $\mathrm{n}=2$ independent experiments using cells from different donors) on basophils was analyzed by flow cytometry. 


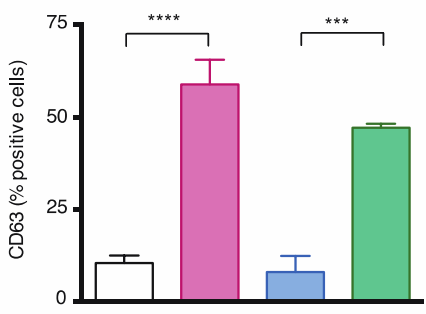

Basophils + IL-3

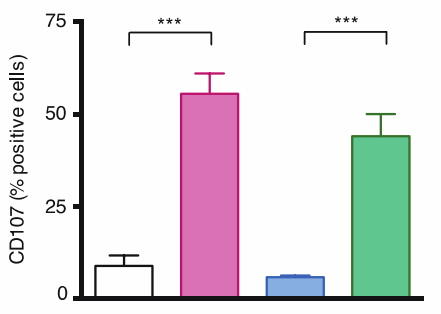

Basophils + Tregs

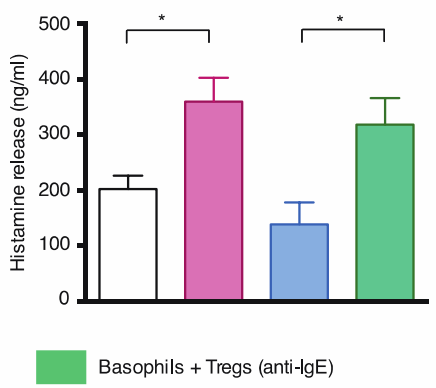

Fig. S10. Tregs license basophils to undergo activation by degranulation signals. Basophils $\left(0.1 \times 10^{6}\right.$ cells $\left./ 200 \mu \mathrm{L}\right)$ were cultured with IL-3 or co-cultured with Tregs at 1:3 ratio for 24 hours in the presence of plate-bound anti-CD3 MAb and soluble anti-CD28 MAb. During last one-hour culture, anti-IgE antibodies $\left(10 \mathrm{ng} / 0.1 \times 10^{6}\right.$ basophils $)$ were added to stimulate the basophils. (A) Expression of CD63 and CD107a (mean \pm SEM, n=4 independent experiments using cells from different donors) on the basophils under various experimental conditions. (B) Amount of histamine released by the basophils (mean \pm SEM, $n=6$ independent experiments using cells from different donors). $* \mathrm{P}<0.05$; $* * * \mathrm{P}<0.001 ; * * * * \mathrm{P}<0.0001$ by one-way ANOVA with Tukey's multiple comparison test. 

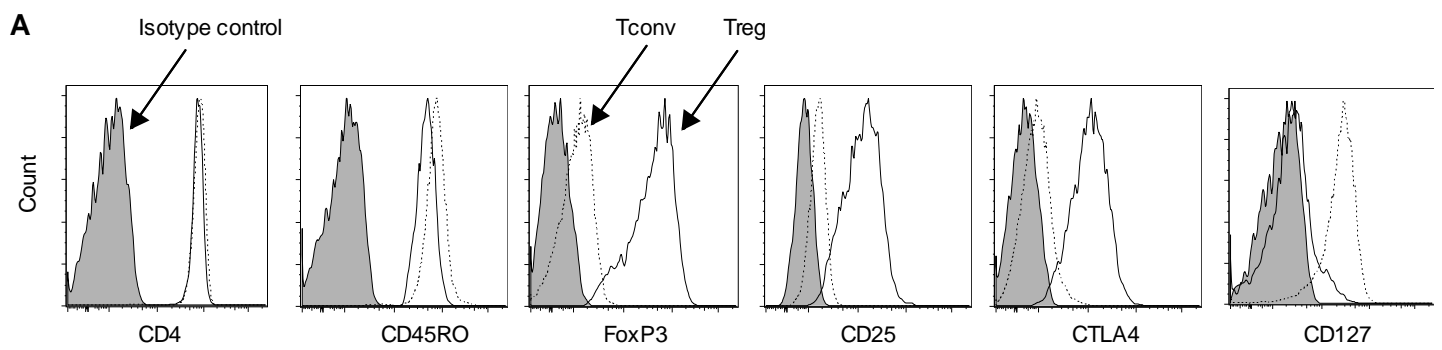

B

Tconv:Treg (1:0)

Tconv:Treg (1:3)

Unstimulated Tconv
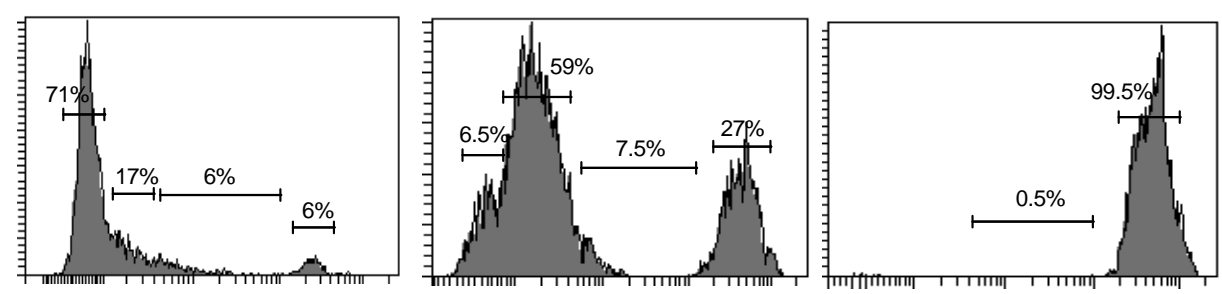

Fig. S11. The phenotypic and functional features of isolated human Tregs. (A) Representative plots depicting the expression (extracellular or intracellular) of CD4, CD45RO, FoxP3, CD25, CTLA-4 and CD127 in isolated Tregs and Tconv cells. (B) Suppression of effector T cell proliferation (Tconv) by purified Tregs. Tconv cells were labeled with CFSE and were cultured in serum-free X-VIVO 15 medium either alone (left panel) or with purified Tregs at 1:3 ratio (middle panel) in the presence of plate-bound anti-CD3 MAb and soluble anti-CD28 MAb. Right panel shows unstimulated Tconv cells. After five days, proliferation of Tconv cells was analyzed based on the dilution of CFSE. 
Positive staining: PI

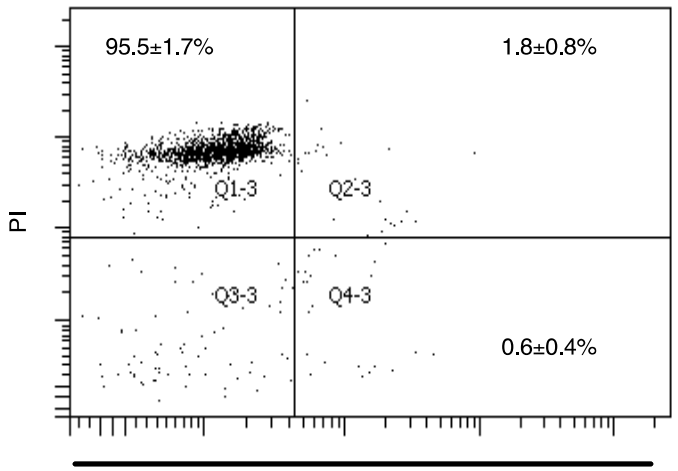

Positive staining: Annexin V

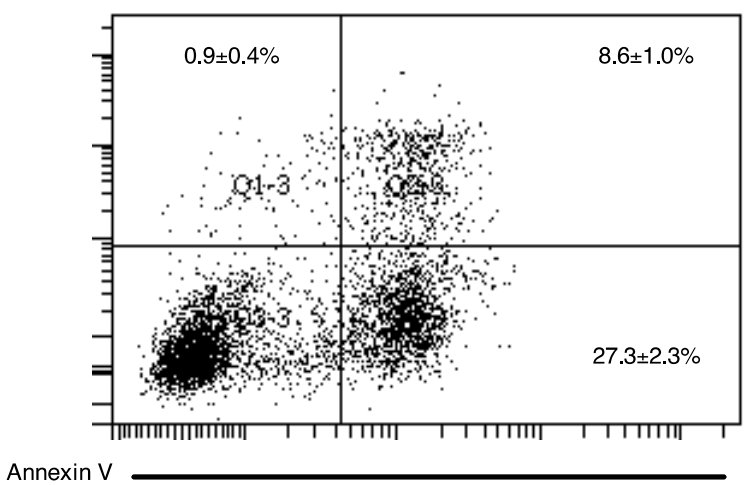

Fig. S12. The positive controls for Annexin V and PI staining. Percentage of Annexin V and PI positive cells (mean \pm SEM, $n=4$ independent experiments) that were cultured with $20 \%$ ethanol for $30 \mathrm{~min}$ (Left panel, Positive staining: PI) or gemcitabine $\left(1 \mu \mathrm{g} / 0.5 \times 10^{6}\right.$ cells) for 24 hours (Right panel, Positive staining: Annexin V). 